ENCUESTA 



\section{ENCUESTA EL TRATADO POR EL QUE SE ESTABLECE UNA
CONSTITUCIÓN PARA EUROPA}

Nuestra revista, fiel a su razón de ser y a su rótulo, ha pretendido siempre mostrarse atenta a la realidad constitucional de cada momento. Y ello implicaba que nuestro número del primer semestre de 2005 habíamos de dedicarlo al estudio de la que se ha dado en llamar La Constitución europea; y a tal fin lo dedicamos con carácter monográfico, aún a sabiendas de que sobre su problemática habremos de volver, por supuesto, en próximos números de esta publicación.

Obviamente se nos podrá objetar que los constitucionalistas nos asomamos a la Constitución europea con menor legitimidad que a cualquiera de las Constituciones que son obra del Poder constituyente que es reflejo de la noción que del mismo acuñaron los revolucionarios franceses. A nadie se le oculta que esta Constitución europea es el fruto de un tratado internacional suscrito por Estados soberanos y sujetos del Derecho Internacional Público, y ella es una de las razones por las que nuestro Consejo de Redacción invitó a contestar la encuesta a algún internacionalista patrio sobresaliente.

Pero los constitucionalistas nos encontramos especialmente interesados por el alcance y los límites de esta denominada Constitución europea. Más allá del debate de si se trata o no de una auténtica Constitución por su origen y naturaleza y del interés de la prensa y de parte de la clase política por maximizar la trascendencia de este Tratado (recordamos, por cierto, que ya sucedió algo parecido con el Tratado de Ámsterdam), lo cierto es que, aún relativizando la condición constitucional del texto, no se pueden desconocer los numerosos impactos que esta suerte de Tratado internacional sistematizador y actualizador de sus antecesores en el ámbito de regulación de esa Confederación moderna y dinámica que es la Unión Europea produce por debajo y por encima de la línea de flotación de las normas políticas fundamentales de los Estados miembros. Repasemos algunos casos bien notorios.

La organización institucional de la Unión Europea afecta inevitablemente a la de los Estados que la integran. Particularmente - por citar un caso muy interesante entre nosotros- ello es relevante en el caso de los Estados federales o en el de nuestro Estado Autonómico, puesto que, si una determinada competencia ha de ser atribuida a las instancias comunitarias, ello se producirá con independencia de que se trate de una competencia estatal o de un Estado miembro (léase Comunidad Autónoma en nuestras latitudes), lo cual a la postre preocupa más a las fuerzas nacionalistas infra estatales que a ninguna otra, pues es obvio que sólo los Estados son sujetos del Derecho Internacional y autores y responsa- 


\section{PREGUNTAS}

1. En qué medida se ajusta el nuevo Tratado a los diversos rasgos característicos tradicionalmente asociados al término Constitución?

2. Las novedades incorporadas al Tratado - personalidad jurídica de la Unión, supremacía del Derecho comunitario, régimen de distribución de competencias, politica exterior y de seguridad, ... - ¿afectan sustancialmente a la posición jurídica de los Estados en el seno de la Unión?

3. El reforzamiento del Parlamento europeo y la incorporación al Tratado de la Carta de derechos fundamentales, ¿satisfacen a su juicio las expectativas de legitimación democrática de la Unión Europea?

4. ¿Cree Vd. que los nuevos procedimientos de decisión incorporados al Tratado permitirán el progreso ulterior de la integración política europea?

5. ¿Se plantearán problemas de coordinación entre los derechos consagrados en las Constituciones de los Estados miembros, el Tratado constitucional para la Unión Europea y el Convenio Europeo de Derechos Humanos?

6. ¿Sería necesario o conveniente reformar la Constitución Española para adaptarla a las disposiciones del nuevo Tratado? ¿En qué extremos?

\section{ENCUESTADOS}

Juan Antonio Carrillo Salcedo, Catedrático de Derecho Internacional Público, Universidad de Sevilla

Luis María Díez-Picazo Giménez, Catedrático excedente de Derecho Constitucional, Universidad de Málaga

Antonio López Pina, Catedrático de Derecho Constitucional y titular de la Cátedra Jean Monnet de Cultura jurídica europea, Unniversidad Complutense de Madrid

Gil Carlos Rodríguez Iglesias, Catedrático de Derecho Internacional Público, Universidad Complutense de Madrid; antiguo presidente del Tribunal de Justicia de la las Comunidades Europeas

1. ¿En qué medida se ajusta el nuevo Tratado a los diversos rasgos característicos tradicionalmente asociados al término Constitución?

\section{JUAN ANTONIO CARRILLO SALCEDO}

Como internacionalista, el término elegido —Constitución- me parece adecuado: así se denomina el Tratado constitutivo de la UNESCO o el de la Organización Internacional del Trabajo. El empleo del término responde a la voluntad de los Estados de utilizar una palabra distinta de las muchas que en la práctica se emplean para denominar a los acuerdos entre Estados regidos por el Derecho internacional y destinados a producir efectos en Derecho internacional. En este orden de cosas, resulta significativo que el Tratado constitutivo de la Sociedad de Naciones se denominara Pacto, o que el constitutivo de la 
bles de esos flujos competenciales. Muchas reservas nacionalistas se han vendido en España con discursos relativos al reconocimiento de lenguas propias, cuando no es descartable que la causa principal de tales resistencias ante la nueva Constitución haya de buscarse en clave del poder expropiatorio de los Estados sobre las competencias descentralizadas políticamente a favor de órganos territoriales internos dotados de autonomía.

De otra parte, el sistema de fuentes del Derecho al que los constitucionalistas españoles de nuestro tiempo venimos dedicando la debida atención, puesto que es parcela crucial del Derecho constitucional, se ve igualmente impactado por el Derecho comunitario, cuya primacía ya era una realidad, que ahora se consagra solemnemente en este Tratado constituyente. El informe al respecto de nuestro Consejo de Estado otorga, como sabemos, a esta cuestión la máxima trascendencia, aunque ulteriormente el Tribunal Constitucional no haya compartido la tesis de la pertinencia de modificar en consecuencia el artículo 9 de nuestra Constitución de 1978.

También en el terreno de la parte dogmática de la Constitución -proclamación y garantía de los derechos y libertades fundamentales- la Unión Europea está muy lejos de ser neutra. Del ya veterano concepto de ciudadanía europea se han derivado consecuencias que bien conocemos acerca de un acerbo común de derechos fundamentales que tienen por titulares a todos los ciudadanos de la Unión y de otros que son propios del correspondiente Estado miembro, pero que son disfrutables en régimen de igualdad por los nacionales de otro Estado miembro en la medida en que residan en aquél.

Las anteriores disgresiones, elementales y desordenadas a un tiempo, quizás sirvan al menos para justificar la oportunidad de este número monográfico sobre una materia, la Constitución Europea, que buena parte de nuestros constitucionalistas siguen pensando, en base a muy sólidos argumentos, que es aún hoy más una pieza del Derecho Internacional Público que del Derecho Constitucional; pero nadie puede negar su relevancia cada vez mayor sobre tal Derecho Constitucional, por muy clásica que quiera ser la visión que del mismo nos formemos.

Es de justicia agradecer muy especialmente a los profesores que nos han honrado con las respuestas que a continuación publicamos y también resulta obligado disculpar de buen grado a quienes han declinado respondernos. Las particulares dificultades que encierra este trance a nadie se le oculta. Mucho celebraríamos, en todo caso, que el debate que pretendemos alentar con esta encuesta sea útil e interesante a los ojos de los restantes profesores y estudiosos de nuestra disciplina. Ese es nuestro modesto pero constructivo propósito. 
con una ligereza impropia del asunto en cuestión, impostar al Tratado la categoría de Constitución.

Tales avales para el empleo del término Constitución son, en estricta dogmática, de dudoso valor. Por un lado, la ampulosidad y vaguedad del concepto de Constitución empleado por el Tribunal de Justicia es tal, que como criterio para responder a la pregunta no nos sirve: en el hecho de que el Tribunal de Justicia haya calificado a los tratados de Carta constitucional, no hay más que una analogía, que se explica, no más que, a causa de que los tratados han venido cumpliendo en la Comunidad europea funciones semejantes a las que la Constitución satisface en los Estados. Por otro, los Jefes de Estado y de gobierno han recurrido con tan calculada ambigüedad a la categoría Constitución que, más que un proyecto de Constitución Europea, lo que el Tratado revela a la luz del día es el intento de enmascarar mediante un noble vestido la propia voluntad desnuda de poder que tantos pasajes del texto dejan entrever.

Pero si no resultan convincentes sea el uso jurisprudencial sea el discurso retórico de nuestros Jefes de Estado y de gobierno, deberemos, a fin de responder a la pregunta, precisar qué diferencia hay entre un tratado institutivo de una organización internacional y una Constitución federal. Esta pregunta se la hace, entre nosotros, Luis $\mathrm{M}^{a}$ Díez - Picazo². Para concluir que las definiciones generalmente aceptadas no permiten trazar una distinción neta entre los conceptos de tratado internacional y de Constitución. A su juicio, el único enfoque viable consiste en comparar los rasgos distintivos, como tipos de normas, del tratado internacional y de la Constitución; ello exige examinar la aprobación, la modificación y la extinción de tratados y constituciones.

Lo que sucede es que, por lo que se refiere a las mismas, tampoco hay una línea de separación nítida entre constituciones federales y tratados institutivos de organizaciones internacionales. Verdad es que, en estas últimas, los Estados tienden a conservar un grado mayor de libertad; pero ello no significa que la diferencia sea decisiva ni, sobre todo, necesaria. ¿Habría que concluir, entonces, que no hay diferencia esencial entre ambos tipos de normas?, se pregunta perplejo Díez-Picazo.

Probablemente, la razón última de la indiferenciación radica en que la identificación de los tratados depende de características externas - sujetos, procedimiento, solemnidades, ... Para identificar las constituciones, en cambio, es preciso acudir a consideraciones materiales.

El autor concluye, así, preguntándose qué les queda de los atributos propios de un Estado independiente a los Estados - miembros de la Unión. A la postre, considera que debe desplazarse el debate a la cuestión de en nombre de quién se ha firmado el tratado.

Por bien documentada que esté, la reflexión del autor acaba dejándonos a deber la respuesta a la pregunta, respecto de la diferencia entre un tratado y una Constitución, con la que había comenzado su análisis. A lo mejor resulta que lo que hemos de plantearnos no es tanto cuáles sean las diferencias relativas entre tratado y Constitución, cuanto qué caracteriza materialmente a ésta, y qué utilidad puede tener para nosotros el concepto.

Y héte aquí que tanto el Tribunal de Justicia como nuestros Jefes de Estado y de gobierno emplean un concepto amplio, de sentido esencialmente descriptivo de Constitución, que difiere significativamente del histórico material, cuya generalización se extiende a raíz de la Revolución Francesa.

Recientemente, se ha planteado Dieter Grimm tal problema, definiendo mediante cinco rasgos un concepto funcional de Constitución que pretende hacer justicia a esta 
Organización de las Naciones Unidas se denomine Carta.

Por otra parte, en lo que concierne al proceso de integración europea el término Constitución ya viene siendo utilizado por buena parte de la doctrina y por el Tribunal de Justicia de las Comunidades Europeas, que en más de una ocasión ha calificado al Tratado de la Unión Europea como «Carta constitucional de una comunidad de Derecho».

\section{LUIS MARIA DIEZ-PICAZO}

Mi posición sobre este punto es conocida, porque he escrito sobre ello. Básicamente, creo que la forma «tratado» no es obstáculo a la sustancia «constitución». Ha habido constituciones recogidas en las más variadas formas: costumbre, ley ordinaria, ley de un país extranjero. ¿Por qué una constitución no podría estar contenida en un tratado? La idea de constitución es una idea material (norma fundamental de un ordenamiento jurídico), por lo que nada se opone, a mi juicio, a hablar de una Constitución para Europa.

Cosa distinta es que la Unión Europea no tenga naturaleza estatal. No es un «superEstado». La comparación con las experiencias federales, que se hace a menudo, funciona bien mientras se trata de examinar relaciones internormativas; pero comienza a fallar en cuanto se analizan otros problemas, como la delimitación del territorio, la atribución de la ciudadanía, el uso de la fuerza, etc. En suma, la Constitución para Europa es la constitución de una entidad no estatal. Y esto es algo a lo que no estamos habituados. Hace falta adaptar la teoría constitucional a lo que se ha llamado «fin del modelo Westfalia».

Hay un último aspecto de la idoneidad de la palabra «constitución» para el nuevo Tratado que instituye una Constitución para Europa: su longitud. Algunos sostienen que una verdadera constitución no puede ser tan larga. Tengo mis reservas. De entrada, históricamente ha habido constituciones bastante largas, a las que nadie ha negado su condición de tales. Baste pensar en la Constitución de Cádiz. Es verdad que en ella se regulaban con detalle cuestiones, como el régimen electoral, que hoy nos parecen de índole subconstitucional; pero para los doceañistas esas cuestiones eran cruciales para tratar de implantar el nuevo sistema liberal. Probablemente, con la Unión Europea ocurre algo parecido: los fundamentos del mercado único, contenidos en la Parte III, son prolijos, pero resultan cruciales en el proceso de integración europea. Hay que asentarlos con el máximo rango normativo.

\section{ANTONIO LÓPEZ PINA}

El Tribunal de Justicia de las Comunidades se ha referido a los Tratados como la Carta constitucional europea. El Tribunal infirió las bases de su concepto de Constitución, como Ordenamiento autónomo respecto de los Estados - miembros, de las limitaciones de soberanía de los Estados y de su decisión de imponer el Derecho europeo a los ciudadanos ${ }^{1}$. Por otra parte, la Convención y las dos recientes Conferencias Intergubernamentales han querido, 1964

1 TJCE Van Gend \& Loos v. Nederlandse Administratie der Belastingen, ECR 1963, 1; Costa v. E.N.E.L, ECR

2 Luis M $M^{\mathrm{a}}$ Diez Picazo, Constitucionalismo de la Unión Europea, Madrid: Civitas, 2000 
La decisión sobre las bases jurídicas no es, pues, un acto de autodeterminación de una colectividad, que se configura como unidad política, sino un acto de heterodeterminación. Que los Estados-miembros sean democracias y que ratifiquen a escala nacional el Tratado no afecta a la realidad de que los ciudadanos no son fuente de las bases jurídicas de la Unión. Y, si bien la Unión no está, en lo que a juridificación del ejercicio del poder se refiere, menos desarrollada que los Estados, incumple, en lo que a legitimación democrática concierne, las condiciones del constitucionalismo moderno. A partir de los criterios del concepto estricto de Constitución, para hacer del Tratado una Constitución, en el pleno sentido de la expresión, falta el componente democrático; la doctrina más solvente ${ }^{4}$ niega, así, que, mientras los Estados continúen reservándose la potestad de la reforma de un tratado, pueda hablarse de Constitución.

Ciertamente, para que Europa pudiera darse una Constitución, harían falta una unidad política y unos ciudadanos políticamente emancipados de los que en estos momentos no disponemos. Europa es entretanto un mercado común, una unión monetaria y cada día más un espacio de libertad, seguridad y justicia. Nuestros Jefes de Estado y de gobierno oponen la máxima resistencia, sin embargo, a que constituyamos Europa como Unión política. Y el hecho es que sólo entonces podrían los ciudadanos y su representación parlamentaria disponer de la competencia de la competencia, restablecer la conexión perdida entre territorio estatal, espacio económico y procura existencial (Böckenförde) y señalar a los Estados el lugar imprescindible, ciertamente, pero no principal que en el orden territorial - comunitario les corresponde.

Hasta ahí, mi coincidencia con Grimm es plena. Ahora bien, el problema medular no consiste, como concluye Grimm, en que las transformaciones en las relaciones entre orden social y poder público hayan dejado atrás el momento histórico culminante de la Constitución, o que no se dén las condiciones para constitucionalizar Europa. Esta vez, se ha dejado dos cosas importantes en el tintero. Por un lado, Grimm detiene en 1949 su concepto de Constitución, y no incorpora al mismo la interpretación jurisprudencial y doctrinal alemana, italiana y española que hace de la garantía de las condiciones materiales de la igual libertad parte esencial de las respectivas constituciones. Pero es que, además, a renglón seguido de disponer de ese concepto material de Constitución, y cuando Grimm parece abandonarse a la resignación de que, de forma semejante al Estado, tenga la Constitución un futuro incierto, es cuando para nosotros comienza la gran tarea: a saber, cómo mantener las tensiones normativas entre la garantía de los derechos que es el legado constitucional europeo, y un Tratado, una forma de producir Derecho y un acervo de Derecho derivado tan alejados de ese concepto material canónico de Constitución. Sobre ello vuelvo en mis respuestas a las preguntas $\mathrm{n}^{\circ} 5 \mathrm{y} \mathrm{n}^{\circ} 6$.

\section{GIL CARLOS RODRÍGUEZ IGLESIAS}

3 Dieter Grimm, «Verfassung - Verfassungsvertrag - Vertrag über eine Verfassung», L'Europe en voie de Constitution. Pour un bilan critique des travaux de la Convention, Sous la direction de O. Beaud; A. Lechevalier; I. Pernice et S. Strudel, Bruxelles: Bruylant, 2004; Dieter Grimm, «Ursprung und Wandel der Verfassung», in Handbuch des Staatsrechts, Isensee; Kirchhof (Hrsg.), 3. Auflage, Band I, Heidelberg: C. F.Müller Verlag, 2003. 
tradición ${ }^{3}$ :

1. Las constituciones son cuerpos de normas jurídicas con pretensión normativa de validez.

2. La vinculación jurídica debe referirse a la institucionalización y al ejercicio del poder público. Lo crean, lo institucionalizan y establecen cómo debe ser ejercido.

3. Fin de la Constitución es tanto la legitimación como la limitación de la autoridad. Como base de legitimación sólo cabe el consenso de los subordinados. Las sociedades fijan en la Constitución los contenidos y formas de su unidad política y designan sobre tales bases las personalidades llamadas al ejercicio del poder. La sociedad que se configura como unidad política es, en consecuencia, el sujeto del poder público.

4. La Constitución regula omnicomprensivamente tanto la legitimidad para los mandatos públicos como las modalidades de su ejercicio. Con ello no se implica una juridificación total de la política. Una Constitución de tales pretensiones disolvería la política en mera ejecución de las normas constitucionales. La Constitución establece solamente principios y procedimientos para el proceso político, no los resultados. La Constitución es omnicomprensiva en la medida en que no tolera poderes y facultades extraconstitucionales. Tal objetivo únicamente puede ser logrado, si la Constitución tiene primacía sobre los actos jurídicos del poder público. Tales actos jurídicos sólo son válidos sobre la base y en el marco de la Constitución. La Constitución vive de tal diferenciación de planos entre las premisas para la adopción de decisiones y éstas.

5. De ahí, la primacía de la Constitución. Sin la misma, la Constitución no podría cumplir su función legitimadora, ni satisfacer sus pretensiones omnicomprensivas de regulación.

Que la necesidad de la juridificación pueda ser satisfecha en la forma de una Constitución depende de que, de un lado, se dén los presupuestos y, de otro lado, sean realizables los fines proclamados. Concretamente para nosotros la pregunta reza, si la Constitución está hasta tal extremo asociada a la forma juridica referida al Estado que no puede ser disociada de éste, o bien, si puede ser traspuesta a unidades políticas no-estatales que ejercen poder público. Dirigida tal pregunta a la Unión Europea, nos encontramos con que, sin que la Unión tenga carácter de Estado, cumple cuatro de tales rasgos. Los tratados son vinculantes, regulan el ejercicio del poder público de la Unión, lo juridifican plenamente y tienen primacía sobre los actos jurídicos de las instituciones comunitarias. De ahí que podamos decir que los tratados cumplen en la Unión Europea funciones que la Constitución satisface en los Estados.

Ahora bien, solamente en cuanto los tratados constituyen la Unión y sus órganos existe legitimación. En tan poca medida como la producción de Derecho, se atribuye el origen de los tratados a los ciudadanos. Los Estados-miembros han concertado, vía contrato, las bases jurídicas de la Unión; los ciudadanos no han participado.

Los Estados-miembros se han reservado, una vez concluido el Tratado, también la potestad de disponer sobre las bases jurídicas de la Unión. El Derecho originario solamente puede ser reformado mediante igual procedimiento que el que se ha seguido para producirlo.

4 Alessandro Pizzorusso, Il patrimonio costituzionale europeo, Bologna: Il Mulino, 2002; Dieter Grimm, op. cit. 
los Derechos Fundamentales.

En tercer lugar, el método de elaboración del proyecto constitucional en el seno de la Convención Europea, al apartarse del modelo tradicional de la conferencia intergubernamental, al introducir en el proceso principios de representación no gubernamentales y al propiciar el debate público sobre los objetivos y los medios de la integración europea, fortalece la legitimidad directa de la Unión Europea sin merma de la legitimidad indirecta canalizada a través de los Estados miembros.

El resultado es una Constitución que, al mismo tiempo, es un tratado internacional y que deriva su legitimidad de una doble fuente: los ciudadanos y los Estados. Sus peculiaridades en relación con el modelo constitucional tradicional derivan en gran medida de su objeto y de su propósito: es la Constitución de una entidad política que no es un Estado ni tiene vocación de serlo, sino que es una Comunidad de Estados y de ciudadanos. Se trata, por consiguiente, de un nuevo modelo constitucional.

2. Las novedades incorporadas al Tratado - personalidad jurídica de la Unión, supremacia del Derecho comunitario, régimen de distribución de competencias, política exterior y de seguridad, ... ¿a afectan sustancialmente a la posición jurídica de los Estados en el seno de la Unión?

\section{JUAN ANTONIO CARRILLO SALCEDO}

Creo que sí afectan, en la medida en que se profundiza en el proceso de comunitarización y se reduce la dimensión de intergubernamentalidad, que no obstante no desaparece ni tiene por qué desaparecer por tratarse de un aspecto, legítimo, en el proceso de integración.

\section{LUIS MARIA DIEZ-PICAZO}

Creo que estas novedades tienen una importancia relativa o, por decirlo de otro modo, no creo que la nueva Constitución para Europa haya modificado radicalmente la naturaleza de la Unión, ni la de las relaciones entre ésta y los Estados miembros. Veamos.

La atribución expresa de personalidad jurídica a la Unión - y no sólo, como hasta ahora, a la Comunidad - es relevante porque permitirá celebrar acuerdos internacionales en materias de los llamados segundo y tercer pilares. Pero poco más. Es verdad que ha habido cierta resistencia a este respecto. Tengo la impresión que ello se debe a que no poca gente en Europa tiene una concepción mística de la personalidad jurídica, como si la naturaleza del poder ostentado dependiera de que su titular sea caracterizado o no como persona jurídica.

En cuanto a la primacía del Derecho de la Unión sobre el derecho de las Estados miembros, creo que es importante su proclamación expresa. Es verdad que ya existe, como principio establecido por la jurisprudencia. Me parece, con todo, que no es indiferente que los Estados miembros lo acepten explícitamente. Si se pone en conexión con la cláusula de retirada unilateral —ésta sí que es una verdadera novedad- cabe captar la naturaleza última del vínculo constitucional: pertenecer a la Unión Europea implica aceptar la primacía incondicionada de ésta, pero esa aceptación es voluntaria en la medida en que cabe abandonar unilateralmente la Unión. 
Antes de abordar la cuestión de la naturaleza constitucional del nuevo tratado quiero recordar que desde hace tiempo los tratados básicos vigentes y en particular el tratado constitutivo de la Comunidad Económica Europea son ya caracterizados como «constitución» no sólo por buena parte de la doctrina jurídica sino también por el Tribunal de Justicia de las Comunidades europeas, que ha calificado al referido tratado como «la carta constitucional de una comunidad de derecho».

El sentido de esta caracterización es el de una calificación analógica que resulta legítima y útil en la medida en que permite poner de manifiesto que los tratados constitutivos desempeñan la función de una constitución en el sistema jurídico de la Comunidad y de la Unión Europea. Esta función constitucional tiene distintas manifestaciones, entre las cuales me parecen especialmente destacables que constituyen la norma suprema en la jerarquía normativa del sistema, el fundamento de las competencias de la Comunidad - y, por consiguiente la norma de delimitación de competencias entre ésta y los Estados miembros-, establecen los principios fundamentales del ordenamiento jurídico comunitario y, en definitiva, son la base de un sistema jurídico que corresponde a las exigencias de un Estado de Derecho, lo que permite que la Comunidad pueda ser considerada y caracterizada como una Comunidad de Derecho, cuyos poderes están sometidos a límites propios de un orden constitucional.

Esta consideración funcional de los tratados como constitución en sentido jurídico tiene sus limitaciones, ya que son tratados internacionales que sólo pueden ser modificados con el consentimiento de todos los Estados miembros, lo cual lleva consigo la necesidad de que cualquier modificación cualitativa del sistema europeo resulte asumible por cada uno de los sistemas constitucionales nacionales. Al mismo tiempo, la legitimidad de la «constitución» comunitaria no es una legitimidad directa, sino mediata, canalizada a través de los Estados miembros.

Casi todas las consideraciones anteriores pueden aplicarse mutatis mutandis al Tratado por el que se establece una Constitución para Europa, que es un tratado internacional regido por las normas del Derecho internacional en cuanto a las condiciones de su entrada en vigor y a los requisitos para su modificación, por lo demás particularmente rígidos en la medida en que se mantiene la exigencia del consentimiento de todos los Estados miembros.

Hay sin embargo elementos constitucionales nuevos que se añaden a las funciones constitucionales que desempeñan ya los tratados vigentes.

En primer lugar, hay una innovación fundamental no sólo desde el punto de vista político, sino también desde el punto de vista jurídico formal: el nombre de Constitución, que, habida cuenta del contexto en el que se ha gestado, no es una mera confirmación de la calificación doctrinal y jurisprudencial de los tratados existentes, sino la expresión de una voluntad política de establecer un texto que, por su función, su contenido y su valor simbólico, tenga una naturaleza constitucional y sea percibido y entendido como tal por el conjunto de los ciudadanos. En mi opinión, la denominación de Constitución tiene alcance normativo y, desde un punto de vista jurídico formal, refuerza y consolida las funciones constitucionales que ya desempeñan los tratados vigentes, al mismo tiempo que, desde un punto de vista político, fortalece la legitimidad de la Unión Europea.

En segundo lugar, junto a otros elementos del contenido del Tratado que refuerzan su naturaleza constitucional, tiene una importancia esencial la incorporación de la Carta de 
reverso; pero tampoco aquí los Estados-miembros han estado dispuestos a avanzar en la comunitarización: la adopción de decisiones descansa sobre la cooperación intergubernamental (art. III-293; art. III-300; I-40 7. y 8. TCpE). Ello significa que cada Estado dispone de derecho de veto.

Con la complicidad, pues, de nuestros Jefes de Estado y de gobierno, Europa renuncia a tener una defensa y una política exterior: el Tratado significa que nos plegamos al designio del capital anglosajón, de reducirnos a la condición de súbditos con un mercado común. Los grandes pronunciamientos sobre el papel de Europa en las relaciones internacionales del Tratado deben ser, así, vistos como meras declaraciones retóricas sin voluntad política de llevarlos a la práctica. En caso de crisis, pues, a nadie debiera ocurrírsele poner sus esperanzas en la Unión Europea.

GIL CARLOS RODRÍGUEZ IGLESIAS

Desde mi punto de vista, el Tratado por el que se establece una Constitución para Europa en términos generales no modifica de modo substancial la posición jurídica de los Estados miembros en el seno de la Unión. Trataré de explicar y matizar esta afirmación con algunas observaciones relativas a los aspectos mencionados en el cuestionario.

En primer lugar, pienso que la atribución de personalidad jurídica a la Unión Europea es, ciertamente, importante como elemento de racionalización del sistema. Hasta ahora cada una de las Comunidades europeas tiene personalidad jurídica propia y la Unión — paraguas conceptual que cubre a las Comunidades europeas y a los dos pilares intergubernamentales (Política Exterior y de Seguridad Común y cooperación judicial y policial en el ámbito penal) no tiene formalmente atribuida personalidad jurídica, aunque el hecho de que existan acuerdos internacionales concluidos en su nombre permite afirmar - y ésta es mi posición personal- que tiene personalidad jurídica internacional. Frente a esta situación compleja la Constitución refuerza considerablemente la unidad institucional ya proclamada en el vigente Tratado de la Unión Europea y consagra una única personalidad jurídica, que se atribuye a la Unión Europea, que sucederá a las distintas personas jurídicas actualmente existente (no sólo en la personalidad jurídica, sino en el conjunto de sus funciones). La atribución de personalidad jurídica a la Unión constituye, pues, una modificación importante, pero, a mi juicio, no afecta de modo significativo a la posición jurídica de los Estados miembros.

Especial atención merece el principio de primacía. Según el artículo I-6, relativo al «Derecho de la Unión», «la Constitución y el Derecho adoptado por las instituciones de la Unión en el ejercicio de las competencias que se le atribuyen a ésta primarán sobre el Derecho de los Estados miembros». Salvo las modificaciones terminológicas resultantes de la referencia a la «Constitución» y a la «Unión», este artículo no introduce innovación substancial alguna en relación con el principio fundamental de la primacía del Derecho comunitario sobre el Derecho interno, que es un principio consagrado por el Derecho vigente y que además es generalmente considerado como uno de los principios característicos del ordenamiento jurídico comunitario junto al de efecto directo.

Hay quienes pretenden relativizar el valor del principio de primacía haciendo referencia a su origen jurisprudencial. Ahora bien, frente a semejante pretensión conviene recordar que el desarrollo jurisprudencial del derecho comunitario forma parte del acervo comunitario («acquis communautaire») que vincula al conjunto de los Estados miembros y que debe ser plenamente asumido por todo Estado al integrarse en la Comunidad. 
El sistema de distribución de competencias es clarificador. Pero no hay que olvidar que no se abandona la doctrina de la base jurídica; es decir, los actos de la Unión continuarán rigiéndose por el precepto de la Parte III que les sirva de fundamento. Y esto diluye el alcance de la definición de un sistema de distribución de competencias.

En fin, la política exterior. Aquí no hay grandes novedades. Lo único digno de mención es que se deja la puerta abierta a una eventual política más integrada.

\section{ANTONIO LÓPEZ PINA}

Es jurídicamente relevante que, de ser la supremacía del Derecho comunitario meramente jurisprudencia consolidada del Tribunal de Justicia, pase, en el art. I-6 TCpE, a estar normativamente establecida; no es, sin embargo, una novedad.

En cuanto a la dotación de personalidad jurídica de la Unión, el régimen de distribución de competencias y la política exterior y de seguridad, no deberían llamar a engaño: la posición jurídica de los Estados sale del Tratado inalterada si no reforzada. En ese sentido, el Tratado no innova sino, más bien, sirve a consolidar hacia el futuro las relaciones establecidas de poder. Cuestión distinta, y no baladí, es que los propios Jefes de Estado y de gobierno hayan decidido por su cuenta, en el Consejo europeo de Salónica y en las dos Conferencias intergubernamentales, que lo que nuestros regímenes constitucionales han sido normativamente hasta ahora pase a ser un capítulo de historia. Pero ello es objeto de la pregunta $\mathrm{n}^{\circ}$ 6. El hecho es que, conforme al Tratado, no hay modificaciones sustanciales en los modos en que los Estados, de un lado, participan en la Unión en condiciones de estatalidad abierta ${ }^{5}$ y, de otro, ven preservada su identidad.

Del régimen de distribución de competencias, el fenómeno más interesante, embarazado de futuro, es la creciente comunitarización del espacio de libertad, seguridad y justicia. De todos modos, en materia de política económica, política fiscal, política social, política de medio ambiente, las decisiones continúan sujetas a la decisión unánime o por mayoría cualificada, y los Jefes de Estado y de gobierno han preservado su poder como señores absolutos de los Tratados.

A guisa de ejemplo, la política exterior y de seguridad común, en la que si, de un lado, los Jefes de Estado y de gobierno, al precio de renunciar a una política europea, mantienen un férreo control, de otro, abdican de cualquier proyecto de emancipación respecto del directorio militar de los Estados Unidos. No es éste el lugar para detallar su regulación. Pero basta, de un lado, atender a la necesidad de consentimiento de todos los Estadosmiembros como condición para adoptar estrategias, posiciones, acciones, acuerdos de la Unión en el Consejo de la Unión y en el Consejo de Ministros (art. I - 40 3., 6. y 7. TCpE) y al papel puramente ornamental asignado al Parlamento (art. I - 40 8. TCpE). De otro, con recordar que los compromisos y la cooperación en este ámbito seguirán ajustándose a los compromisos adquiridos en el marco del Tratado del Atlántico Norte, que seguirá siendo, para los Estados miembros que forman parte de la misma, el fundamento de su defensa colectiva y el organismo de ejecución de ésta (art. I - 41 7. TCpE). La defensa tiene la política exterior como

5 Cfr. R.Wahl, «Der offene Verfassungsstaat als Staatstyp der Gegenwart», in Festschrift für H. Kuriki, publicado en japones id., «Die zweite Phase des öffentlichen Rechts in Deutschland. Die Europäisierung des öffentlichen Rechts», Der Staat 38. Band 1999 H. 4 
En lo que se refiere al régimen general de distribución de competencias, que en la Constitución está mejor definido que hasta ahora, me parece claro que no lleva consigo ninguna modificación substancial de la posición de los Estados miembros.

Tampoco me parece que resulte una modificación substancial de la posición de los Estados miembros de las disposiciones de la Constitución que se refieren a la Política Exterior y de Seguridad Común. A pesar de su indudable importancia para reforzar esta política y de las potencialidades que encierran, siguen consagrando un régimen netamente intergubernamental, lo que se pone de manifiesto en que el principio de unanimidad sigue siendo básico en este campo, no obstante algunas excepciones limitativamente señaladas. Más importante que estas excepciones es la «pasarela» contemplada en los artículos I-40, apartado 7, y III-300, apartado 3, disposiciones que permiten al Consejo Europeo, mediante decisión unánime, extender el ámbito en el que el Consejo puede pronunciarse por mayoría cualificada, pero no considero que la existencia de la «pasarela» constituya una modificación substancial.

Mucho más importantes son los cambios que afectan al Espacio de Libertad, Seguridad y Justicia. En este ámbito se continúa el proceso de comunitarización del antiguo «tercer pilar» que se había iniciado ya con el Tratado de Ámsterdam. En efecto, se generaliza el principio de la decisión por mayoría cualificada en el Consejo y la codecisión con el Parlamento Europeo, así como la iniciativa de la Comisión, y, además, se amplían las competencias de la Unión y se establece la base jurídica para la creación de una Fiscalía europea. Al mismo tiempo se extiende el control judicial en este ámbito, hasta ahora sometido sólo parcialmente a un control jurisdiccional específico y más limitado que el aplicable en el ámbito comunitario. Aunque subsisten limitaciones que siguen recordando el carácter inicialmente intergubernamental de la cooperación establecida en este sector, puede estimarse que la comunitarización llevada a cabo lleva consigo una modificación substancial de la posición jurídica de los Estados miembros.

El Consejo Constitucional de Francia ha estimado en su reciente Decisión de 19 de Noviembre de 2004 que distintas disposiciones de la Constitución europea, entre las que se encuentran algunas relativas no sólo al Espacio de Libertad, Seguridad y Justicia, sino también a la Política Exterior y de Seguridad Común -en particular la «pasarela»— exigen la revisión de la Constitución francesa por afectar a las condiciones esenciales de ejercicio de la soberanía nacional. Ahora bien, el criterio aplicado por el Consejo Constitucional es que necesitan una revisión constitucional «las cláusulas del tratado que afectan a las condiciones esenciales de ejercicio de la soberanía nacional en ámbitos o según modalidades distintos de los previstos por el artículo 88-2». Este artículo de la Constitución francesa, cuya redacción actual es resultado de sucesivas revisiones constitucionales relacionadas con modificaciones de los tratados comunitarios, establece literalmente en su primer párrafo que «a reserva de reciprocidad y según las modalidades previstas por el Tratado de la Unión Europea firmado el 7 de Febrero de 1992, Francia consiente en las trasferencias de competencias necesarias para el establecimiento de la Unión económica y monetaria europea» y, en su segundo párrafo, que «con la misma reserva y según las modalidades previstas por el Tratado constitutivo de la Comunidad Europea, en su redacción resultante del Tratado firmado el 2 de Octubre de 1997, pueden ser consentidas las transferencias de competencias necesarias para la determinación de las reglas relativas a la libre circulación de personas y a los ámbitos que le están vinculados». Esta redacción, que vincula el fundamento cons- 
Concretamente el principio de primacía ha sido siempre recordado de forma expresa y destacada en los dictámenes en que la Comisión se ha pronunciado sobre la adhesión de cada uno de los Estados que han ido incorporándose a las Comunidades europeas.

A este respecto resulta significativo que un Estado que, sin tener constitución escrita, tenía un problema constitucional de envergadura en relación con el principio de primacía, lo resolvió en el momento de la adhesión con una solución legislativa muy imaginativa. Me refiero naturalmente al Reino Unido, donde el principio fundamental de la soberanía del Parlamento era radicalmente incompatible con la primacía del Derecho comunitario, ya que dicho principio excluye que el Parlamento pueda limitar la libertad de sus sucesores en el ejercicio de su suprema potestad legislativa. Es evidente que una supremacía del poder legislativo concebida en esos términos implica, a diferencia de la supremacía de una Constitución escrita, un riesgo permanente (más bien certeza) de conflictos frecuentes con el Derecho comunitario, ya que, en tanto que una Constitución escrita tiene vocación de estabilidad, se adoptan nuevas leyes continuamente. Por eso en el Reino Unido se promulgó la «European Communities Act», una ley que, de forma pragmática, aseguró de derecho y de hecho la efectividad de la primacía del Derecho comunitario.

Otro elemento a destacar en relación con el principio de primacía del Derecho comunitario es que se trata de un principio reconocido por los tratados vigentes. En efecto, el apartado 2 del Protocolo sobre la aplicación de los principios de subsidiariedad y proporcionalidad, anexo al Tratado constitutivo de la Comunidad Europea (Protocolo que ha sido introducido por el Tratado de Ámsterdam) dispone textualmente que «la aplicación de los principios de subsidiariedad y proporcionalidad ... no afectará a los principios desarrollados por el Tribunal de Justicia en lo que se refiere a la relación entre el Derecho comunitario y el nacional ......

En suma, considero que la proclamación expresa de la primacía de la Constitución y del Derecho de la Unión no supone una modificación substancial de la posición de los Estados miembros en la Unión Europea.

Añadiré algunas observaciones sobre la problemática del conflicto entre Constitución nacional y Derecho comunitario, pues es cierto que la jurisprudencia constitucional de algunos Estados miembros ha identificado ciertos límites constitucionales a la primacía del Derecho comunitario. A este respecto siempre he sostenido que un conflicto radical entre Constitución nacional y Derecho comunitario es un conflicto hipotético, ya que el Derecho comunitario integra por la vía de los principios generales los valores constitucionales fundamentales de los Estados miembros. De hecho, la jurisprudencia constitucional a la que acabo de hacer referencia ha dado lugar a divergencias dogmáticas con respecto a la del Tribunal de Justicia, pero no a conflictos concretos entre Derecho constitucional nacional y Derecho comunitario. Por otra parte, distintas disposiciones de la nueva Constitución europea refuerzan expresamente la comunidad de valores.

Ciertamente no se puede excluir totalmente la posibilidad de que, en un supuesto concreto, la aplicación de una disposición de la Constitución nacional pueda entrar en colisión con una norma comunitaria, como ocurrió con la disposición de la Constitución alemana que limitaba el acceso de las mujeres a las fuerzas armadas. En tales casos la norma comunitaria debe recibir aplicación preferente, tanto según el Derecho vigente hoy como de conformidad con la Constitución europea. La proclamación expresa del principio de primacía en el nuevo texto constitucional no constituye una modificación, pero debería servir para eliminar las reticencias hacia dicho principio. 
es un verdadero parlamento. Y, por ello, en la medida en que las decisiones básicas pasan por él, no veo déficit democrático alguno. El problema es, más bien, que los europeos se habitúen a ello; es decir, es preciso que vaya surgiendo una opinión pública a nivel continental. Pero no hay que engañarse: nunca la unificación política fue precedida de una opinión —y, menos aún, de una cultura - unitaria. El demos es consecuencia de la existencia de instituciones políticas comunes.

Una última observación sobre la democracia y la Unión Europea: el proceso de integración europea ha consistido, en alguna medida, en la neutralización política en ciertos ámbitos. Piénsese, por ejemplo, en la moneda única, que debe ser administrada por un Banco Central independiente. Personalmente, pienso que es bueno que sea así, que la Unión Europea suponga una cierta restricción del «demonio» de la pasión política.

\section{ANTONIO LÓPEZ PINA}

La forma de gobierno de la Unión que resulta del Tratado queda lejos de responder satisfactoriamente a los cánones de la teoría democrática.

Hasta el Tratado de Mastrique (1993), la doctrina y la opinión pública europea se habían dado por satisfechas con una arquitectura jurídica determinada por el objetivo sectorial de conseguir un mercado común. La unificación de Alemania (1989-1990) sacude las conciencias y los planteamientos doctrinales, subrayando, de un lado, las limitaciones del método Monnet de construcción funcional de Europa ${ }^{6}$; de otro, el déficit democrático de la producción de Derecho y de la adopción de decisiones. Del principio de subsidiariedad y el procedimiento de codecisión para el Derecho derivado (Consejo de Ministros y Parlamento) a la extensión de las materias a decidir por mayoría; de la ampliación de las competencias del Parlamento y la publicidad del Consejo de Ministros-legislador a la ciudadanía europea; de la cohesión económica y social a la Carta europea de derechos; todo ésto comprenden las consecuencias que, de Mastrique (1993) y Amsterdam (1997) vía Niza (2000) a Roma (2004), se han mostrado nuestros Jefes de Estado y de gobierno dispuestos a conceder.

Nadie puede decir que no sean significativos pasos adelante, y que la institucionalización e integración de Europa se hayan paralizado. Y, sin embargo, la forma europea de gobierno continuará siendo una construcción a medias mientras, de un lado, no se constituya Europa como Unión política y, de otro, no gocen los ciudadanos, orígen último de la legitimidad de todo poder, de plenitud de derechos. Puede, al respecto, ilustrarnos, observar la relación entre el estatuto de los ciudadanos y el principio democrático.

a) De la regresión al arquetipo liberal-conservador decimonónico

En la Carta se relacionan los derechos de los europeos. De lo que se trata es de precisar en qué medida los derechos civiles, sociales y políticos del Tratado componen, en su conjunto, un estatuto de la ciudadanía que haga justicia al principio democrático que forma asimismo parte de la civilización europea.

El espacio dedicado a asuntos de libertad, justicia y seguridad plantea las preguntas decisivas de quiénes son titulares de la libertad y la seguridad que se trata de proteger, y de a quién se trata de hacer justicia. Toda el área así definida trasluce preocupación por la segu- 
titucional de la transferencia de competencias al objeto y modalidades definidas en un determinado tratado lleva necesariamente al doble criterio utilizado por el Consejo Constitucional y a la necesidad de proceder a una revisión constitucional cada vez que se produzca la transferencia de una competencia nueva o la modificación de las condiciones de ejercicio de una competencia ya transferida, es decir prácticamente siempre que haya una modificación de los tratados constitutivos.

En suma, considero que el Tratado por el que se establece una Constitución para Europa tiene un alcance bastante más limitado que el del Tratado de Maastricht en lo que se refiere a la afectación de la posición jurídica de los Estados. Sin embargo consagra un cambio cualitativo fundamental, a saber la constitucionalización formal de la Unión Europea.

3. El reforzamiento del Parlamento europeo y la incorporación al Tratado de la Carta de derechos fundamentales, ¿satisfacen a su juicio las expectativas de legitimación democrática de la Unión Europea?

\section{JUAN ANTONIO CARRILLO SALCEDO}

Sin duda, pues la Carta — que ya fue proclamada en Niza y ahora se incorpora al Tratado-, da precisión jurídica a los valores sobre los que la Unión se fundamenta, enunciados en el artículo I-2 del Tratado.

Por otra parte, me parece evidente que el Tratado aumenta las competencias del Parlamento Europeo, una de las instituciones en las que, junto con la Comisión y el Tribunal de Justicia, se expresa otra de las legitimidades en presencia: la de la supranacionalidad.

\section{LUIS MARIA DIEZ-PICAZO}

La Carta, hoy Parte II, tiene que ver más con el Estado de Derecho que con la democracia en sentido estricto. Me parece que es bueno que la Unión Europea tenga su propio catálogo de derechos fundamentales. ¿Se producirán interferencias con las constituciones nacionales y con el Convenio Europeo de Derechos Humanos? Por supuesto que sí. Pero esas interferencias se producen ya. Piénsese en las sentencias del Tribunal Europeo de Derechos Humanos que examinan, directa o indirectamente, actos comunitarios ... Y, aun así, la Constitución para Europa ordena la adhesión de la Unión en cuanto tal al Convenio Europeo. La existencia de dos catálogos de derechos a nivel europeo, sin duda, producirá roces; pero también llevará a un afán de superación.

Cosa distinta es la influencia de la Carta sobre las constituciones nacionales. Teóricamente, la Carta sólo se aplica a las instituciones de la Unión Europea y a las autoridades nacionales cuando apliquen derecho europeo. Sin embargo, no se debe olvidar que toda declaración de derechos es, por su propia naturaleza, una fuerza centrípeta. Gozar de unos mismos derechos es unificador.

Por lo que se refiere a la legitimación democrática, creo que el Parlamento Europeo 
teras, el empleo, el consumo, a las que se otorga el rango de prerrogativas ciudadanas. Y, ni siquiera cuando vota en elecciones locales llega el europeo a ser un ciudadano en el auténtico sentido de la expresión. Como concepto, la ciudadanía europea suspende la congruencia histórica en los Estados entre res publica, nacionalidad y ciudadanía, quedando más cerca de la idea de nacionalidad, que de la de plena emancipación y participación política en las decisiones europeas que correspondería a quiénes son sujetos de derechos fundamentales y libertades públicas. Tal disociación recuerda demasiado precedentes del Estado liberal anterior a 1867, como para que no contraste con la conciencia jurídica del tiempo.

Sin perjuicio de tales insuficiencias, nuestros Jefes de Estado y de gobierno ban dejado en la letra del Tratado, sin embargo, algunos cabos sueltos susceptibles de abrir vías a la emancipación ciudadana:

a) Si no se interpreta el concepto de complementariedad del art. I-10 TCpE, en el sentido de competencia soberana exclusiva de los Estados miembros de la Unión para otorgar la nacionalidad, bien pudiera ofrecer una vía para conciliar la disociación entre ciudadanía y nacionalidad. En la medida en que los Estados-miembros han caracterizado como abierta la ciudadanía europea, han dotado a la misma de una capacidad transformadora. No debería ignorarse la dinámica propia de los Tratados: una vez ratificados, los Estados-miembros pierden el control sobre la interpretación y aplicación de las normas. En tal sentido, el Tratado, propuesto en el contexto más amplio de transformación del Estado-nación histórico, somete también la ciudadanía nacional a transformación (Wandelverfassung, Ipsen, H. P., 1972).

b) Un desplazamiento de pesos en el sistema general de equilibrios se apunta, asímismo, en el Tratado, donde se dice, los partidos politicos a escala europea ... contribuyen a la formación de la conciencia europea y a expresar la voluntad política de los ciudadanos de la Unión (art. I-46.4 TCpE) y que una ley europea regulará los partidos políticos a escala europea (art. III-331 TCpE).

Ello significa tanto como que la voluntad política autónoma de los ciudadanos (art. I-1 TCpE) ha sido, con independencia de los Estados, incorporada al Derecho originario de la Unión.

\section{c) El principio de homogeneidad constitucional}

De todos modos, tal estatuto de la ciudadanía solo permite caracterizar a Europa como Unión no-democrática. Entretanto, la falta de legitimación popular resulta demasiado flagrante. En momentos de riesgo de bloqueo institucional a la hora de adoptar importantes decisiones políticas, no cabe por más tiempo que la igualdad en el derecho al sufragio quede a las puertas de Europa. Bienvenidos sean la transparencia y el derecho a la información como vinculaciones al ejercicio del poder público, pero, para la falta de democracia que aqueja a la Unión, no sabrían ser un Ersatz suficiente.

En efecto, desde la Declaración sobre Identidad Europea en materia de condiciones para ser miembro de la Comunidad, de Copenhague (1973), y desde el art. 6 TUE, los Estadosmiembros quedan comprometidos a respetar los derechos humanos y velar por la autenti- 
ridad. Buena parte de lo que constituye el espacio está sometida a acuerdos intergubernamentales y continúa bajo control de los Estados-miembros: el art. III-436 TCpE abre una generosa excepción de la generalidad del espacio a los Estados; el control democrático en los Estados-miembros es por demás limitado y son reducidas las posibilidades de control judicial (art. I-42; III -270 a 274 TCpE).

A primera vista, el área de libertad, justicia y seguridad evoca, así, la versión liberal histórica de libertad frente al Estado. Ésta está estrechamente ligada a la idea de libertad negativa de mercado, bajo la cual la ciudadanía de la Unión comporta protección de la actividad económica privada frente a la injerencia de los Estados. La vocación originaria de la Comunidad de alcanzar un mercado común habría venido, así, a reforzar la reducción de la ciudadanía a las libertades del mercado.

Tal visión negativa de la libertad como libertad económica frente al Estado no empece a la sensibilidad social de la Unión. Lo que sucede es que, aún cuando el Tratado suponga progresos respecto de los de Mastrique, Amsterdam y Niza, queda muy por detrás del ideal de condiciones materiales universales de la igual libertad de todos los ciudadanos — lo que significa bastante más que el minimalismo de la igualdad de oportunidades social-liberal. Este modelo solo parcialmente responde a la idea de la ciudadanía social, legada por von Stein, los Webbs, Heller, Beveridge y T. H. Marshall ${ }^{7}$. Ésta iba más allá: la igual libertad va necesariamente de la mano de una institucionalización de la ciudadanía política. Con el Tratado, tenemos solamente una Unión social limitada de Derecho, que no entra necesariamente en contradicción con la suerte de construcción conservadora de Estado de Derecho que, en materia de libertad, seguridad y justicia, acabamos de ver. Antes bien, es coherente con una concepción social -liberal del Estado-gendarme - la de Bismarck, en la Alemania Guillermina, sin ir más lejos.

\section{b) Derechos políticos}

Para que la opinión pública europea asumiera los derechos civiles y sociales en los insuficientes términos plasmados en el Tratado de Mastrique, los gobernantes habían de ofrecer alguna que otra compensación política. Ello explica, de un lado, la ciudadanía europea, de otro, la transparencia y el derecho a la información.

Ahora bien, si no podían por menos los Jefes de Estado y de gobierno de haber de pagar el peaje de otorgar la ciudadanía, nunca debería ésta por su voluntad, sin embargo, traducirse en plena emancipación política. Y, así, los derechos y deberes conferidos a los ciudadanos están más ligados a la residencia en un Estado miembro que a la Unión: no se traduce la ciudadanía en una relación entre la Unión y sus ciudadanos o en un vínculo entre los ciudadanos mismos; más bien, se segmentan ciertas actividades, el viaje a través de fron-

7 Cfr. Stein, L. von, Geschicbte der sozialen Bewegung in Frankreich von 1789 bis auf unsere Tage, Leipzig, 1850; en lengua española, Movimientos sociales y Monarquía, Prólogo de Luis Díez del Corral; traducción de Enrique Tierno Galván, Madrid: Instituto de Estudios Políticos, 1957; Webb, S., Labour and the New Social Order, 1918; Industrial Democracy, 1897; Heller, H., Politische Demokratie und soziale Homogenität; Rechtsstaat oder Diktatur?; Bürger und Bourgeois, Gesammelte Schriften, Ch. Müller (Hrsg.), zweite Auflage, Zweiter Band, Tübingen: J. C. B. Mohr (Paul Siebeck), 1992; en lengua española, H. Heller, Escritos políticos, Edición, prólogo y epílogo de A. López Pina, Madrid: Alianza Editorial, 1985; Beveridge, W., Report. Full Employment in a Free Society, London: 1944; Marshall, T. H., Citizenship and Social Class, London, 1950; publicado posteriormente en el libro Class, Citizenship and Social Development, New York: Doubleday \& Co., 1964 
nismos de la Unión. Hay que reiterar sin embargo con respecto a estas disposiciones la misma cautela que en relación con el fortalecimiento del Parlamento Europeo como factor de refuerzo de la legitimidad democrática: su impacto dependerá del grado de efectividad de la puesta en práctica de estos principios. Por ejemplo, el apartado 4 del artículo 46, según el cual «los partidos políticos de dimensión europea contribuirán a formar la conciencia política europea y a expresar la voluntad de los ciudadanos de la Unión», puede quedar reducido a una manifestación de buenas intenciones, como ha ocurrido hasta ahora con el artículo 191 del vigente Tratado constitutivo de la Comunidad Europea, del que apenas se distingue. Considero, en efecto, que uno de los obstáculos más importantes para que el Parlamento Europeo despliegue todas sus potencialidades de legitimación por la vía de la democracia representativa radica en la nacionalización del debate político europeo y de las elecciones al Parlamento Europeo, nacionalización cuyos principales responsables son los partidos políticos nacionales que dominan el espacio político.

Finalmente me parece que también el método de elaboración del proyecto constitucional en la Convención Europea es un factor que refuerza la legitimidad democrática de la Unión.

4. ¿Cree Vd. que los nuevos procedimientos de decisión incorporados al Tratado permitirán el progreso ulterior de la integración politica europea?

\section{JUAN ANTONIO CARRILLO SALCEDO}

Sí, pues la regla de la mayoría cualificada tiene ahora mayor ámbito de aplicación, en la medida en que se reducen los supuestos en los que la decisión ha de ser adoptada por unanimidad.

\section{LUIS MARIA DIEZ-PICAZO}

En cuanto a los nuevos procedimientos de toma de decisiones, mi opinión es que es bueno que haya un procedimiento legislativo ordinario, aplicable salvo excepción en contrario; y es bueno que ese procedimiento consista en la codecisión entre Parlamento Europeo y Consejo.

Menos positiva es mi valoración del nuevo sistema de voto en el Consejo: la doble mayoría, básicamente porque España es indudablemente perdedora en ello. Dicho esto, hay que reconocer que el viejo sistema del voto ponderado debía ser modificado, pues era excesivamente complejo. Además, cada nueva ampliación exigía una complicada negociación para calcular el valor del voto de cada Estado.

En otro orden de consideraciones, aunque siempre en sede de procedimientos, me parece que el mantenimiento del principio de unanimidad para las futuras revisiones de la nueva Constitución para Europa, especialmente en una Unión ya con veinticinco miembros, hará que el texto sea excesivamente rígido. 
cidad democrática de sus regímenes políticos. Más explícitos resultan los arts. 6, 7 y 49.1 TUE del Tratado de Amsterdam. Ello supone, sin embargo, sólo el perfil del principio de homogeneidad constitucional más destacado por la doctrina dominante.

No menos necesario que requerir de los candidatos a la Unión o de los Estadosmiembros el respeto a los valores consagrados en el Tratado parece, sin embargo, afincar la democracia comunitaria en las tradiciones constitucionales de los países miembros. Sacando, así, las consecuencias últimas del art. 23 GG o de la unión constitucional, hay que llegar a la mayor homogeneidad constitucional posible entre la Unión y los Estados miembros. Pues el llamado déficit democrático y sus efectos en la división de poderes es un gran tema pendiente de la Unión al que el Tratado, sin embargo, no ofrece solución. En cuanto concierne al principio democrático — resumidamente, derecho igual de sufragio, legitimidad popular y responsabilidad política del ejercicio del poder-, el orden comunitario y la forma europea de gobierno apenas se han abierto a las tradiciones constitucionales de los Estados miembros.

Por ejemplo, el único modo de lograr la representación proporcional de los ciudadanos europeos sería prescindir de la distribución de los escaños entre Estados, pasando a configurar circunscripciones electorales que transcendieran las fronteras y que, sin perjuicio de las pertinentes consideraciones funcionales, tuvieran en cuenta el criterio de población. Para que pueda hablarse de igualdad en el ejercicio del derecho de sufragio, condición imprescindible para una auténtica ciudadanía democrática, es preciso no sólo que el voto emitido en los diferentes Estados tenga un peso equivalente, sino también un régimen electoral uniforme en todo el territorio. Sin embargo, tal régimen uniforme no ha sido adoptado; y, entretanto, es preciso atenerse a las reglas establecidas en los diversos Estados. Ello supone la confirmación de que el Parlamento Europeo, pese a ser directamente elegido por los ciudadanos y pretender por ello la representación democrática a escala europea, representa en realidad, como reconocía el Tratado de la Comunidad Europea, a los pueblos de los Estados y no a los ciudadanos europeos de la Unión. Los procesos electorales ponen de relieve que se trata, fundamentalmente, de la agregación de diversas elecciones de ámbito estatal, y apenas de la celebración de unas elecciones europeas en las que los asuntos de la Unión ocupen el lugar central que les corresponde.

\section{GIL CARLOS RODRÍGUEZ IGLESIAS}

El fortalecimiento de la posición del Parlamento Europeo en el equilibrio institucional es un factor decisivo para reforzar la legitimidad democrática directa de la Unión Europea. Naturalmente este refuerzo será más o menos sólido según sea más o menos satisfactorio el funcionamiento efectivo del Parlamento.

Más importante aún como factor de legitimación de la Unión Europea es la constitucionalización de la Carta de los Derechos Fundamentales, que conferirá más certeza a los derechos protegidos y los hará más visibles y que además tiene un gran valor simbólico.

Hay otros elementos en el texto constitucional que son también relevantes desde este punto de vista. Destacaré especialmente el título VI de la parte I, denominado «De la vida democrática de la Unión» y, dentro de él, los artículos 45 a 47, relativos a los principios de igualdad democrática, de democracia representativa y de democracia participativa, así como el artículo 50, relativo a la transparencia de los trabajos de las instituciones, órganos y orga- 
impuesto, bastará que algunos Estados sigan defendiendo ese modelo, tan ajeno al modelo europeo de sociedad, para que la situación sea incontrovertible. Del mismo modo, lo grave no es que los grandes objetivos de la Europa social —el derecho al trabajo, el pleno empleo, la eliminación de la precariedad, la renta mínima garantizada - no figuren hoy en el Tratado, sino que será suficiente que, en el futuro, un solo Estado se oponga, para que hayamos de renunciar a ellos. Lo grave no es que la disparidad fiscal instale en la construcción europea la injusticia como base de la realidad socioeconómica, sino que esa injusticia la hagan algunos Estados muy dificilmente eliminable. Lo grave no es que Europa renuncie a ser la conciencia ecológica del mundo y la impulsora de un desarrollo sostenible, sino que esa renuncia resulte definitiva. Lo más grave de todo no es ya que Europa no pueda tener, en estos tiempos de guerras, una política exterior de paz, autónoma e independiente de los Estados Unidos, que, en el segundo mandato de Bush, aumentará previsiblemente sus obsesiones bélicas y el número de víctimas civiles, sino que, gracias a la unanimidad y a la OTAN, será prácticamente imposible poner fin a ese seguidismo guerrero (J.Vidal Beneyto, Por una Europa política, social y ecológica, EL PAIS, 6 Nov. 2004).

Miguel Angel Moratinos saldrá, como portavoz del Gobierno, en defensa del procedimiento europeo de adopción de decisiones como garantía de las minorías y del Tratado, en general, como respuesta a la necesidad de hacer frente a inmensos desafíos (Miguel Angel Moratinos, Por la mejor Europa siempre posible (a mi buen amigo Pepin Vidal-Beneyto), EL PAIS, 11 Noviembre 2004)

c) El protocolo de tales pronunciamientos tiene el sentido de enmarcar mi respuesta. Pues bien, encandilados con las luces de Niza y Roma, sería cándido por nuestra parte ignorar las sombras: en román paladino, en lo que a forma de gobierno de Europa se refiere, estamos asistiendo a la puesta en escena de una ley de hierro de la oligarquía de cuatro candados, cuya llave se reservan los Jefes de Estado y de gobierno. Es un secreto a voces que, en la clandestinidad de los Consejos de Ministros y del Consejo de la Unión, aquéllos truecan vetos y concesiones como si de su patrimonio privado se tratara. La imposición a todo trance de los intereses nacionales tiene el efecto de un pasador con cuatro candados, que nuestros príncipes ponen a la Unión de ciudadanos igualmente libres.

aa) el primer candado lo encontramos en la Comisión (arts. I-26-27 TCpE), en forma de resistencias a reducir el número de comisarios. Detrás de tales actitudes se revela la voluntad decidida de considerar a los comisarios como representantes del Gobierno nacional de turno. Ello resulta tanto más llamativo, cuanto que desnaturaliza el designio, de los founding fathers, de la Comisión como institución de iniciativa legislativa y vocación europea creada para trascender los intereses nacionales.

bb) El segundo candado, en el Consejo Europeo, lo apreciamos no sólo en el cierre a toda publicidad, la preservación del derecho de veto y la resistencia al control político (arts. I-21-23 TCpE), sino también en la ponderación de votos (art. I -25 TCpE) desproporcionadamente desfavorable a los pequeños Estados - lo que se compadece mal con la idea de una garantía de minorías en lo que después de todo es una cámara territorial.

cc) El tercer candado consiste en la composición nacional de un Parlamento Europeo, al que continúan negándose la plena responsabilidad presupuestaria y el control político del Ejecutivo.

dd) Pero nuestros Jefes de Estado y de gobierno no debían considerarse del todo seguros, y creyeron necesario añadir un cuarto candado sobre la reforma constitucional (art. IV-443 TCpE). Una buena Constitución no consiste sino en un conjunto de reglas y de 


\section{ANTONIO LÓPEZ PINA}

Los Jefes de Estado y de gobierno que, en Niza y las dos últimas conferencias intergubernamentales, han tejido en nombre del interés nacional un proceso tan arduo de adopción de decisiones (art I-25 TCpE), no pueden ahora dolerse de que, justo tal norma, haya puesto en evidencia la voluntad desnuda de poder que los embarga. El debate sobre el particular está abierto y el foro público europeo y español registra división de opiniones. No teniendo mayor sentido responder al margen del contexto a la pregunta, trataré de resumirlo como marco de mi respuesta.

a) Voces autorizadas, en España y extramuros, propugnan con argumentos evidentes rechazar el Tratado, justo, porque incapacita a la Unión para decidir y porque, mediante el requisito de la unanimidad para la reforma, petrifica el status quo. El debate de mayor consistencia sobre el particular acaba de tener lugar con los resultados conocidos en el seno del Partido Socialista francés. Para su visualización por la doctrina española puede tener sentido traer aquí algunos testimonios.

Sin duda, hay argumentos a favor del Tratado, como los que han aportado recientemente Lionel Jospin, Dominique Strauss-Kahn o Jack Lang. Si para éste, la unanimidad que se requiere para ratificación y reforma del Tratado no es un obstáculo (justo tal unanimidad nunca ha impedido a Europa progresar a lo largo de cincuenta años), el primero entiende que el planteamiento de una crisis salvífica es una quimera y que se trata de un compromiso aceptable.

Entre quiénes han manifestado reservas al Tratado, la personalidad de mayor peso es Laurent Fabius, antiguo Primer ministro bajo la Presidencia de François Mitterrand y candidato a la Presidencia de la República francesa. A su juicio, el Tratado hace improbable la organización de Europa en tres círculos concéntricos, necesaria para el progreso de Europa, habida cuenta de las condiciones restrictivas para las cooperaciones reforzadas; mientras que la unanimidad requerida para toda modificación ulterior del Tratado amenaza paralizar el futuro de Europa, diluída entretanto en un proceso indefinido de ampliación. Este Tratado amenaza con encadenarnos por décadas; mejor sería hacernos con otras bases, que preserven la capacidad de Europa para un gran proyecto político. Rechazando el Tratado con mi voto, replica Arnaud Montebourg a Jack Lang, no habré prestado mi acuerdo a este estado de impotencia, y estas relaciones fácticas no habrán sido solemnizadas por el sufragio universal. Decir SI no es aprobar un compromiso, sino firmar una capitulación, responde Jean-Luc Melénchon a Lionel Jospin.

b) Pero también en España acaba de abrirse el debate. Para Vidal Beneyto, el texto responde a la lógica de poder de los Estados. Pero esa voluntad de mando y control no se confina al presente, sino que compromete la política futura de la Unión, que se quiere siga rigiéndose por las preferencias ideológicas de los gobiernos que han presidido su redacción y firma. Sobre todo, que nada pueda cambiar. Lo cual tenía que conducir a una Constitución de acuerdos mínimos y, además, irreversibles. De ahí que todas las cuestiones importantes y conflictivas se hayan sometido al régimen de la unanimidad o de la mayoría cualificada. Por ello, lo grave no es consolidar ahora el modelo económico del monetarismo liberal conservador y confirmar la autonomía y los poderes, prácticamente absolutos, del Banco Central Europeo; cuando cambien la ideología y el color político de los gobiernos que los han 
política al que nos dirigimos a largo plazo, no está determinado jurídicamente ni por los tratados vigentes ni por el nuevo Tratado por el que se establece una Constitución para Europa.

Creo que el hecho de tener una Constitución constituirá un factor que propicie la integración política, pero la concreción de este objetivo exige la continuación del debate constitucional, que no quedará agotado con la entrada en vigor de esta Constitución.

5. ¿Se plantearán problemas de coordinación entre los derechos consagrados en las Constituciones de los Estados miembros, el Tratado constitucional para la Unión Europea y el Convenio Europeo de Derechos Humanos?

\section{JUAN ANTONIO CARRILLO SALCEDO}

Surgirán problemas, pero no insalvables por el intérprete. En todo caso, el Tratado dispone expresamente en su artículo I-9.2 que la Unión se adherirá al Convenio Europeo de Derechos Humanos.

\section{LUIS MARIA DIEZ-PICAZO}

Véase la respuesta a la pregunta tercera

\section{ANTONIO LÓPEZ PINA}

Al respecto, tres extremos merecen especial consideración: a) la definición de los derechos; b) el Convenio Europeo de Derechos Humanos; c) la relación entre Derecho constitucional y Derecho europeo en materia de derechos fundamentales

a) La definición e interpretación de los derechos

Una vez entrado en vigor el Tratado, la Carta sería jurídicamente vinculante. El art. II-112.7 TCpE añade que las explicaciones elaboradas para guiar la interpretación de la Carta de derechos fundamentales serán tenidas debidamente en cuenta por los órganos jurisdiccionales de la Unión y de los Estados miembros.

Pero el propio art. I-9 TCpE consagra la construcción jurisprudencial preexistente, y contempla la protección de los derechos fundamentales como principios generales del Derecho de la Unión. Ello implica que los derechos podrían continuar siendo reconocidos y delimitados por la jurisprudencia del Tribunal de Justicia, que habrá de tomar como fuente de inspiración las tradiciones constitucionales de los Estados-miembros y el Convenio Europeo de Derechos Humanos. En el propio Preámbulo, la Carta reconoce que no nace ex nibilo, sino que es un eslabón más de una cadena en la que le han precedido el Convenio Europeo de 
instituciones; por otra parte, suficientemente abierto como para ser capaz de adaptarse a las transformaciones de la sociedad que pretende regir. De ahí la importancia del procedimiento de reforma, especialmente respecto de un texto desproporcionadamente detallado. Si el mismo resulta demasiado fácil, fomentará la inestabilidad; de ser rígido en exceso, por el contrario, bloqueará su evolución. Es este segundo riesgo el que el Tratado hace correr a la Unión. No se trata sólo de la complejidad del procedimiento de reforma. El requisito del acuerdo unánime de los Estados — sea de los gobiernos, sea de los Parlamentos nacionales o de los ciudadanos convocados a referendum de ratificación- impide que una mayoría de ciudadanos y de Estados de Europa deseosos de una reforma puedan imponerse: el requisito de la unanimidad hace de los tratados textos prácticamente irrevisables. Ello pone en cuarentena el futuro de la Unión.

El equilibrio institucional de poderes ha resultado desde 1957 intermitentemente operativo en episodios aislados protagonizados sea por el Parlamento Europeo o por el Tribunal de Justicia, sea por la Comisión. Aún así, en cuanto forma política, se trata de un modelo desfasado, cuyo tiempo y lugar son el período previo a la Unión Política que, desde Mastrique (1992), hemos dejado atrás. Entretanto, el equilibrio entre Comisión, Consejo Europeo y Parlamento es tan confuso que no solamente hace inasumible una precipitada ampliación, sino que maniata a Europa, incapacitándola para adoptar decisiones y actuar. Nuestra Unión es un régimen político intrincado, en el que autovestidos de la prerrogativa de señores privados de los Tratados, los Jefes de Estado y de gobierno hacen predominar, frente al bien común, los intereses nacional-particulares. Los cuatro candados afectan así a los fundamentos mismos de la construción europea. Si después de dos décadas de ambigüedad calculada, queremos recuperar la capacidad de llamar a las cosas por su nombre, no podemos por menos de constatar que el Tratado confirma como forma real europea de gobierno el asalto del mercado contra la democracia.

En efecto, la reforma del voto por mayoría en el Consejo de Ministros y la redistribución de escaños en el Parlamento se evidencian, en última instancia, como no más que una cosmética del reforzamiento de las posiciones de poder de los Jefes de Estado y de gobierno en el propio Estado, en el Consejo de Ministros y en el Consejo de la Unión. Nuestros Jefes de Estado y de gobierno, autoinvestidos de su condición de señores de los Tratados, nos otorgan a los ciudadanos un régimen político confuso que acaba mostrando a la luz del día sus vínculos de vasallaje con el capital y el mercado, consolidados en la Parte III del Tratado. Al desnudo, el Tratado tiene no poco de patrimonialización de la Unión Europea y de privatización del Derecho público por nuestros gobernantes, en contrapunto a las aspiraciones a igual y solidaria libertad de los ciudadanos.

\section{GIL CARLOS RODRÍGUEZ IGLESIAS}

A pesar de las grandes discusiones que sobre los procedimientos de decisión ha habido tanto en la Convención como en la Conferencia intergubernamental no creo que tales procedimientos vayan a resultar determinantes para el proceso de integración a largo plazo.

A mi juicio la Constitución responde a la necesidad de reforzar la legitimidad democrática de la Unión en su vertiente de legitimidad conferida por los ciudadanos en el momento actual del proceso de integración, más en razón de lo ya alcanzado que de lo que aún debe ser alcanzado. El objetivo final del proceso de integración, el grado de integración 
del contenido esencial, en la medida en que define con carácter vinculante para los Estados el alcance de ciertos derechos que ninguna justificación constitucional puede luego desconocer. Ésa ha sido asimismo la fórmula operativa en el Derecho comunitario, y es la propuesta por el art. II-112.3 TCpE: En la medida en que la presente Carta contenga derechos que correspondan a derechos garantizados por el Convenio Europeo para la Protección de los Derechos Humanos y de las Libertades Fundamentales, su sentido y alcance serán iguales a los que les confiere dicho Convenio. Esta disposición no obstará a que el Derecho de la Unión conceda una protección más extensa. Por supuesto, ello no excluye que en algunos casos (como en la extensión de la garantía de la inviolabilidad de domicilio a las personas jurídicas, que Estrasburgo parece afirmar en términos que provocan extrañeza en Luxemburgo) se plantéen problemas de interpretación y aplicación.

El art. I-9 TCpE añade que la Unión se adherirá al Convenio Europeo para la Protección de los Derechos humanos y de las Libertades fundamentales. Los problemas que este trámite plantea son de dos tipos, técnicos y políticos; los primeros, en algún caso de difícil solución, quizás no supongan obstáculos insalvables, toda vez que el Derecho acostumbra a procesar ciertas inseguridades. Los segundos tienen un calado mayor, y sólo con reservas y cautelas podrán ser eludidos.

Así, los problemas de coordinación procesal han sido planteados ante la jurisprudencia constitucional española en casos concretos que la han obligado a tomar en cuenta la jurisprudencia de Estrasburgo - aún despues de haber rechazado el recurso de amparo en el mismo caso. Por ello no se convierte el Tribunal Constitucional en un órgano judicial ejecutor de las resoluciones en materia de derechos humanos del Tribunal de Estrasburgo, del mismo modo que éste no es una instancia de casación; simplemente, el Tribunal Constitucional se encarga de atribuir a una resolución internacional los efectos que en Derecho interno le corresponden, de acuerdo con los tratados ratificados por España. La reciente sentencia del Bundesverfassungsgericht (Aktenzeichen 2 BvR 14801/04, publicada el 19-10-04, sobre Umgangsrecht eines Vaters mit seinem Kind) que subraya la posibilidad de que ciertos obstáculos de Derecho interno a la plena eficacia de las sentencias del Tribunal Europeo de Derechos Humanos sean insalvables, podría no estar alejada de estos razonamientos. Tampoco cabría descartar una similar articulación en el caso del Tribunal de Justicia. Los conflictos, en cualquier caso, no resultan ser sólo hipotéticos, como pone de manifiesto la sentencia del Tribunal Europeo de Derechos Humanos en el caso Matthews (1999).

Cuestión distinta hubiera sido la referencia directa de los Tratados a la Convención como integrante del Derecho originario. Ello hubiera supuesto introducir directamente una jurisdicción internacional como jurisdicción interna, atribuyéndole la específica facultad de decidir sobre, por ejemplo, el respeto de las políticas comunitarias a los derechos fundamentales. Pero esto no sólo defiere una función constitucional, en forma inadecuada, a una jurisdicción no concebida al efecto. También colocaría al Tribunal de Estrasburgo, formado parcialmente por jueces de paises extracomunitarios, como juez del Derecho comunitario, en términos de paridad con el Tribunal de Justicia. En la medida en que de la ratificación por la Unión Europea de la Convención Europea de Derechos Humanos pudiera extraerse tales consecuencias, tal interpretación debería ser excluida.

c) Relación entre el Derecho constitucional y el Derecho europeo en materia de derechos fundamentales 
Derechos Humanos y la jurisprudencia del Tribunal de Justicia; más aún, la Carta reconoce que su finalidad última es expresar de forma más visible los valores comunes a cuya preservación y desarrollo quiere servir la Unión. En tal sentido, va a ser difícil negar a la Carta el carácter de condensación documental de las tradiciones constitucionales de los Estados-miembros.

El propio Tratado prevé igualmente que la Unión se adherirá al Convenio Europeo para la Protección de los Derechos Humanos y de las Libertades fundamentales. Las reservas a la adhesión al Convenio, expuestas en su momento por el Tribunal de Justicia, son salvadas por el art. I-9.2 TCpE mediante la precisión de que esta adhesión no modificará las competencias de la Unión que se definen en la Constitución.

El art. II-113 TCpE añade: Ninguna de las disposiciones de la presente Carta podrá interpretarse como limitativa o lesiva de los derechos humanos y libertades fundamentales reconocidos, en su respectivo ámbito de aplicación, por el Derecho de la Unión, el Derecho internacional y los convenios internacionales de los que son parte la Unión o todos los Estados miembros, y, en particular, el Convenio Europeo para la Protección de los Derechos Humanos y de las Libertades Fundamentales, así como por las constituciones de los Estados-miembros.

En su caso, la eficacia de la Carta se superpondrá, pues, a la garantía deducida conforme a los principios generales del Derecho europeo, elaborados por el Tribunal de Justicia, y a la derivada de la adhesión de la Unión al Convenio Europeo de Derechos Humanos. También se prescribe que los derechos reconocidos en las constituciones estatales deberán ser garantizados.

A tan complejo régimen de identificación de los derechos protegidos, que sin duda va a plantear problemas materiales de interpretación, se añade la co-existencia de un triple orden jurisdiccional, en principio, competente para determinar el alcance de los respectivos documentos de garantía. Pues, en efecto, los derechos vinculan no sólo a las instituciones comunitarias, sino asímismo a los Estados en la medida en que actúen en ejecución o desarrollo del Derecho comunitario, e incluso sólo en el marco del Derecho comunitario - cuya proclividad a la expansión, por ejemplo, a efectos del mercado único, resulta difícil de acotar. Dado que en los Estados-miembros son igualmente vinculantes tanto los derechos fundamentales establecidos en las respectivas constituciones como los reconocidos en el Convenio Europeo de Derechos Humanos, ello comporta la existencia simultánea de tres jurisdicciones, cuyas relaciones recíprocas deben ser precisadas.

b) El Convenio Europeo de Derechos Humanos

Similar es el problema que plantea la interiorización en la Unión Europea y en los Estados del Convenio Europeo de Derechos Humanos. En ambos casos, se trata de comprobar, de un lado, la influencia material que puede atribuirse a sus cláusulas y a la jurisprudencia del Tribunal de Estrasburgo en la interpretación y el desarrollo del propio Ordenamiento; de otro, la eficacia formal de sus disposiciones en el supuesto de que la Unión se haya adherido al Convenio.

La influencia del Convenio como criterio para orientar el desarrollo jurisprudencial en el Derecho comunitario de los derechos fundamentales cuenta ya con una larga tradición. En los Estados, las exigencias del Convenio han sido entendidas como una suerte de reforma constitucional por adición; en España, se ha propuesto, así, que se extraiga de la jurisprudencia de Estrasburgo el límite absoluto a los límites de los derechos, en términos de la doctrina 
Unión y, en su caso, tras la correspondiente cuestión prejudicial. A partir de ahí, se considerará solamente si la limitación es constitucionalmente admisible a partir del parámetro general sentado por las sentencias Maastricht y Solange II. De este modo, el definido como estándar minimo de derechos constitucionales se impondría a las instituciones de la Unión, en cuanto sus actos tengan eficacia en el seno de los Estados, mediante un control constitucional concurrente con el propio del Derecho comunitario. La eventual dualidad de controles sobre unos mismos actos postula una cooperación entre Tribunales, que el Bundesverfassungsgericht se ha apresurado a ofrecer, y que, por el momento, discurre por los pacíficos cauces establecidos por la Bananen-Entscheidung, de 7 de Junio del 2000. Fracasarán tanto los recursos de amparo como las cuestiones de inconstitucionalidad planteados por causa de supuestas lesiones del Derecho de la Unión a derechos fundamentales si el demandante no prueba que el Derecho europeo vulnera con carácter general y sistemático el mencionado estándar. El Tribunal Constitucional no llevará a cabo su tarea a través de un control de casos particulares.

En resumen, el papel de los derechos fundamentales reconocidos en la Constitución alemana sería pues residual en un doble sentido: de un lado, sólo entran en juego plenamente cuando no se está en el ámbito de las competencias transferidas a la Unión Europea. De otro, en el caso de las competencias transferidas, sólo podrían invocarse como estándar general frente a un desarrollo del Derecho europeo que no satisficiera el parámetro valorativo que proporciona la declaración constitucional de derechos fundamentales considerada en su conjunto.

En cualquier caso, las tensiones sobre el alcance y la interpretación atribuidos a los derechos por ambas jurisdicciones suelen ser excepcionales. Para anticipar esta valoración a partir de la experiencia, debe tenerse en cuenta, en primer lugar, cómo concibe el Derecho comunitario los derechos fundamentales bajo su régimen: los retrotrae a unas tradiciones constitucionales heterogéneas, y que, por tanto, no permitirían suponer que la coordinación entre los diversos Derechos constitucionales y el Derecho comunitario fuera a producirse siempre de modo aproblemático. Los derechos fundamentales cobran su específico sentido precisamente en el marco de cada uno de los concretos ordenamientos constitucionales, y resulta difícil, si no imposible, atribuirles uno al margen de los demás elementos que configuran la estructura de cada Estado constitucional.

Lo cierto es que la jurisprudencia de Luxemburgo es insatisfactoria en muchos extremos. Una de las explicaciones es el desproporcionado peso que el Tribunal de Justicia atribuye a la perspectiva institucional, en cuanto impone la consideración preferente de los fines de la Unión frente a la garantía subjetiva de los derechos fundamentales. La interpretación y aplicación de éstos se acomoda a los objetivos generales de la integración; la propia posición de los individuos es funcionalizada al servicio del interés comunitario, en particular atribuyendo a los particulares medios procesales que les permitan imponer la eficacia del Derecho europeo. Schoch ha hablado, en este sentido, de la unidimensionalidad estructural del Derecho comunitario, que no compensaría debidamente la tutela de los intereses generales y la garantía de los particulares.

De todos modos, las tensiones admiten una cierta composición. Son así innegables coincidencias fundamentales de los criterios de procesamiento dogmático, en términos que permiten seguramente atender a la necesidad objetiva de que los Derechos constitucional y comunitario sean considerados en este extremo desde las exigencias de una 
Por lo que se refiere a la relación en materia de derechos fundamentales entre el Derecho constitucional y el Derecho europeo, hay que subrayar que los derechos reconocidos por el Tribunal de Justicia de la Unión se imponen cotidianamente a partir de los principios que regulan las relaciones entre Derecho estatal y Derecho comunitario. Si el juez ordinario no tutela un derecho reconocido por el Derecho comunitario, ello no abre la vía del recurso de amparo ante el Tribunal Constitucional, por más que el derecho en cuestión pueda constar en la tabla española de derechos. La sentencia Apesco entiende que el único canon admisible para resolver las demandas de amparo es el precepto constitucional que proclama el derecho o libertad cuya infracción se denuncia y no el Derecho comunitario. Esta jurisprudencia se matiza, por ejemplo, en la STC 130/1995: el derecho de configuración legal en cuestión se entiende integrado, en tal contexto, no sólo por las normas nacionales o convencionales, sino tambien mediante el Derecho comunitario.

El problema puede plantearse, en particular, cuando el Derecho comunitario imponga limitaciones de los derechos que cabría considerar inconstitucionales, pero que resulten conformes a los principios más laxos del Derecho comunitario. La primacía del Derecho comunitario priva de márgenes, frente a los actos de la Unión, para la tutela de los derechos fundamentales reconocidos en las respectivas constituciones. Cuando la jurisprudencia alemana halló en la actividad de las autoridades comunitarias riesgos de que fueran violados los derechos garantizados frente a los poderes públicos por la Ley Fundamental de Bonn, formuló la advertencia en la célebre sentencia Solange I, de 1974: entretanto (solange) los derechos fundamentales no fueran garantizados en el marco del Ordenamiento comunitario, el propio Tribunal Constitucional alemán asumiría su tutela tomando como criterio las disposiciones establecidas al respecto por la Ley Fundamental de Bonn. Una reserva similar había planteado la Corte Costituzionale italiana el año anterior (caso Frontini).

Que el Tribunal de Justicia de las Comunidades desde el caso Hauer (1979), se esforzara en desarrollar los derechos reconocidos en las tradiciones constitucionales comunes a los Estados miembros y en la Convención Europea de Derechos Humanos como principios generales del Derecho comunitario, permitió al Tribunal Constitucional alemán constatar que la garantía de los derechos en Derecho comunitario era similar a la dispensada por los Estados. Por ello, suspende la reserva formulada en Solange I mediante la sentencia Solange II, de 1986, mientras (solange) tal garantía perdure. Ello puede el Bundesverfassungsgericht mantenerlo incluso una vez que él mismo resafirmara, en la Maastricht-Entscheidung (12 Octubre 1993), la propia reserva de competencia en garantía general de un estándar indisponible de derechos, sobre los actos de los órganos comunitarios - y no sólo en el control de constitucionalidad de los actos de los órganos estatales que los complementan o desarrollan. Tampoco ha sido nunca puesta en juego la reserva que la Corte Costituzionale italiana prevé para el caso de que una norma del Tratado de la Comunidad Europea, tal como es interpretada y aplicada por las instituciones y órganos comunitarios, resulte contraria a los principios fundamentales de nuestro Ordenamiento o atente contra los derechos inalienables de la persona (caso Fragd).

La cuestión no está, pues, claramente resuelta con carácter general; sí, en cambio, cuentan ciertos países con criterios que permiten abordarla. Así, en Alemania, los actos de ejecución del Derecho comunitario que, en virtud del mismo, limiten derechos constitucionales, deben, primero, probar su validez conforme al Derecho comunitario. Sobre el particular decide el juez ordinario, teniendo en cuenta los derechos fundamentales reconocidos en la 


\section{GIL CARLOS RODRÍGUEZ IGLESIAS}

Sin duda se plantearán algunos problemas.

En la Carta de los Derechos Fundamentales y en la Parte I de la Constitución hay algunas disposiciones que deberían evitar el conflicto entre los distintos regímenes de protección de derechos fundamentales y propiciar su complementariedad. Puede decirse incluso que esas disposiciones confieren un status constitucional en la Unión Europea tanto al Convenio Europeo de Derechos Humanos como a las tradiciones constitucionales comunes a los Estados miembros en relación con la protección de los derechos fundamentales.

A este respecto hay que citar en primer lugar el apartado 3 del artículo I-9, según el cual «Los derechos fundamentales que garantiza el Convenio Europeo para la Protección de los Derechos Humanos y de las Libertades Fundamentales y los que son fruto de las tradiciones constitucionales comunes a los Estados miembros forman parte del Derecho de la Unión como principios generales.»

Esta disposición viene a codificar la actual jurisprudencia del Tribunal de Justicia sobre las fuentes de protección de los derechos fundamentales en el ordenamiento comunitario y deja claro que, a pesar de que esta jurisprudencia ha sido desarrollada en un contexto caracterizado por la ausencia de un catálogo normativo formal de derechos fundamentales, la constitucionalización de la Carta no desplaza a las fuentes tradicionales constituidas por los principios generales que hunden sus raíces en las constituciones nacionales y en las normas internacionales que vinculan a los Estados miembros.

En la propia Carta tienen especial relevancia algunas disposiciones del Título VII («Disposiciones generales que rigen la interpretación y aplicación de la Carta»), en concreto los apartados 3 y 4 del artículo II-112, que pueden ser comparados al artículo 10, apartado 2 de la Constitución española. Conforme al apartado 3, «En la medida en que la presente Carta contenga derechos que correspondan a derechos garantizados por el Convenio Europeo para la Protección de los Derechos Humanos y las Libertades Fundamentales, su sentido y alcance serán iguales a los que les confiere dicho Convenio. Esta disposición no obstará a que el Derecho de la Unión conceda una protección más extensa». Según el apartado 4, «En la medida en que la presente Carta reconozca derechos fundamentales resultantes de las tradiciones constitucionales comunes a los Estados miembros, dichos derechos se interpretarán en armonía con las citadas tradiciones». Por otra pare el artículo II-113, relativo al «nivel de protección», establece que «Ninguna de las disposiciones de la presente Carta podrá interpretarse como limitativa o lesiva de los derechos humanos y libertades fundamentales reconocidos, en su respectivo ámbito de aplicación, por el Derecho de la Unión, el Derecho internacional y los convenios de los que son parte la Unión o todos los Estados miembros, y en particular el Convenio Europeo para la Protección de los Derechos Humanos y de las Libertades Fundamentales, así como por las constituciones de los Estados miembros».

La interpretación de estas disposiciones no está exenta de dificultades. Con frecuencia la protección judicial de un derecho fundamental exige su ponderación con exigencias de interés general o con el derecho fundamental de otra persona, bienes jurídicos con los que entra en colisión. En tales situaciones la aplicación del criterio de la protección más extensa puede ser ardua en la medida en que la extensión de la protección de un derecho funda- 
interpretación reciprocamente conforme (Hesse). El art. 112.4 TCpE señala expresamente: En la medida en que la presente Carta reconozca derechos fundamentales resultantes de las tradiciones constitucionales comunes a los Estados miembros, dichos derechos se interpretarán en armonía con las citadas tradiciones. El Tribunal de Justicia puede, como hasta ahora, procesar la tradición constitucional de los Estados-miembros a partir de un sustrato mínimo, que en cada caso se combina con aspectos diversos irrenunciables para los Estados, en términos que la casuística y la concreción de la jurisprudencia permiten flexibilizar en la medida necesaria. Las palabras de Gil Carlos Rodriguez Iglesias son ilustrativas en ese sentido: los derechos se ballan judicialmente en un proceso que se desarrolla sobre la base de una comparación crítica y valorativa de los sistemas jurídicos nacionales —valoración que incluye el examen de la jurisprudencia relevante-y culmina con una opción jurisprudencial del propio Tribunal de Justicia que se gesta en el proceso de deliberación. La Carta europea, que quizás no permite superar todos los problemas imaginables en torno a la concepción de los derechos, garantiza normativamente la flexibilidad. Al excluir en el art. II-113 TCpE que las disposiciones de la Carta se interpreten en el sentido de delimitar, con carácter general, los derechos reconocidos por las constituciones de los Estados, decae el valor potencialmente conflictivo de eventuales fórmulas quizás insatisfactorias en algún extremo.

El límite de la interpretación conforme de los derechos comunitarios en su relación con el Derecho constitucional de los Estados reside, más bien, en la diferente concepción subyacente a ambos. Mientras que los derechos constitucionales determinan, conforme a la tradición del constitucionalismo nacida en 1789, la legitimidad y las tareas del poder público, los derechos comunitarios ocupan en la práctica un rango subordinado al de las libertades comunitarias — libre circulación de mercancías, personas, servicios y capitales - de alcance limitado al tráfico económico. Tales libertades comunitarias imponen una unilateral perspectiva económica en la consideración de las actividades y relaciones humanas. La integración europea propende, en efecto, a una unificación de todo el Ordenamiento jurídico relativo a la propiedad, al régimen económico y a las relaciones laborales; la Unión Europea ofrece desarrollo y tutela, así, solo de un cierto elenco de libertades económicas. Pero, dada la prevalencia de tales libertades comunitarias orientadas hacia fines económicos, queda relegado el desarrollo de tareas públicas específicas — de servicio público o de regulación- en garantía de la efectividad de los derechos fundamentales. Por lo demás, dado que el Derecho comunitario prevalece sobre la ley nacional, apenas queda margen al Derecho de los Estados para una procura autónoma del bien común (Böckenförde), al menos en los términos que en los años cincuenta y sesenta se ha desarrollado en el marco del Estado social ${ }^{8}$.

Ciertamente, el Tratado nos ofrece una relación de principios y valores que corresponden plenamente al universo simbólico de la democracia. De ellos deriva una paleta de objetivos: paz, seguridad, desarrollo sostenible, solidaridad y respeto entre los pueblos, eliminación de la pobreza, comercio libre y equitativo, conformidad con el Derecho internacional. Pero luego, en la Parte III, se olvida de los mismos y se centra en celebrar la competitividad y en asegurar la estabilidad de los precios, prohibiendo cualquier restricción a la libre circulación de capitales sin, ni siquiera, abordar los dumping social y fiscal. La solidaridad desaparece del cuerpo normativo como un valor que no encuentra acomodo dispositivo en el marco de las políticas de la Unión? 
mental puede implicar el sacrificio de otro derecho igualmente fundamental o de un objetivo de interés general digno de protección.

Por otra parte, la existencia de distintos órganos jurisdiccionales no integrados jerárquicamente que tienen la misión de proteger los derechos fundamentales reconocidos por su propio orden constitucional es un factor que lleva consigo el riesgo de divergencias, especialmente en la ponderación de los distintos derechos en caso de colisión.

En lo que se refiere a las relaciones entre el Tribunal de Justicia de las Comunidades europeas y el Tribunal Europeo de Derechos Humanos, hay que resaltar que, en la actualidad, el primero aplica sistemáticamente las disposiciones del Convenio Europeo de Derechos Humanos como si fuesen parte integrante del Derecho comunitario y lo hace sobre la base de la interpretación de esas disposiciones consagrada por la jurisprudencia del Tribunal Europeo de Derechos Humanos. La constitucionalización de la Carta de los Derechos Fundamentales podría poner en peligro esta tendencia armónica, toda vez que las disposiciones de la Carta serán la referencia constitucional suprema en materia de derechos fundamentales en el ámbito de la Unión Europea. Sin embargo, además de las disposiciones de la propia Carta antes mencionadas, hay que tener en cuenta el mandato imperativo de adhesión de la Unión Europea al Convenio Europeo de Derechos Humanos establecido en el artículo I-9, apartado 2, de la Constitución. La adhesión implicará que el Tribunal de Justicia de la Unión Europea quedará sometido al control del Tribunal Europeo de Derechos Humanos en relación con el respeto del Convenio en las mismas condiciones en que lo están los tribunales supremos y constitucionales de todos los Estados miembros del Consejo de Europa, lo que en definitiva confirmará la mayor autoridad de la jurisprudencia del Tribunal de Estrasburgo en materia de derechos humanos y deberá reducir la probabilidad de divergencias jurisprudenciales. Esta es una de las razones, no la única, que me han llevado a propugnar desde hace muchos años la adhesión de la Comunidad al Convenio Europeo de Derechos Humanos.

Podría haber más problemas de divergencias jurisprudenciales entre el Tribunal de Justicia y los tribunales constitucionales nacionales. A este respecto pienso que la entrada en vigor de la Constitución europea debería eliminar cualquier tipo de reservas a la aceptación de que, en el ámbito de aplicación del Derecho comunitario, los derechos fundamentales protegidos son los reconocidos por esa Constitución, cuya interpretación autorizada corresponderá al Tribunal de Justicia. Ahora bien, la determinación de dicho ámbito de aplicación y su consiguiente delimitación con respecto al ámbito de aplicación de los derechos fundamentales reconocidos por la Constitución nacional no está exenta de dificultades.

Según el artículo II-111, apartado 1, «Las disposiciones de la presente Carta están dirigidas a las instituciones, órganos y organismos de la Unión, dentro del respeto del principio de subsidiariedad, así como a los Estados miembros únicamente cuando apliquen el Derecho de la Unión. Por consiguiente, éstos respetarán los derechos, observarán los principios y promoverán su aplicación, con arreglo a sus respectivas competencias y dentro de los límites de las competencias que se atribuyen a la Unión en las demás Partes de la Constitución». La lectura de esta disposición permite prever problemas de interpretación que corresponderá resolver al Tribunal de Justicia, en su caso sobre la base de cuestiones prejudiciales cuyo planteamiento difícilmente podrán omitir los tribunales constitucionales nacionales que hasta han sido reticentes a utilizar esta vía (conviene observar que no es el caso de todos los tribunales constitucionales o con jurisdicción constitucional). 
Ahora bien, considero que, más allá de la necesaria delimitación de los ámbitos de aplicación de las distintas normas y de las esferas de competencia de los distintos tribunales, es claro que la proliferación de sistemas de protección de los derechos fundamentales y de órganos jurisdiccionales encargados de su tutela exige un esfuerzo de cooperación por parte de estos tribunales para evitar divergencias que, aun cuando puedan ser jurídicamente explicables, resulten incomprensibles para los ciudadanos. Afortunadamente no se trata de emprender un camino nuevo, sino de continuar el proceso de convergencia que ya desde hace años viene dando lugar a la formación progresiva de un espacio constitucional europeo, especialmente visible en materia de derechos fundamentales.

\section{6. ¿Sería necesario o conveniente reformar la Constitución Española para adaptarla a las disposi- ciones del nuevo Tratado? ¿En qué extremos?}

\section{JUAN ANTONIO CARRILLO SALCEDO}

Sí, pero no respecto de las dos primeras de las cuestiones planteadas por el Gobierno en su consulta al Tribunal Constitucional, cuyo origen se encuentra en el dictamen del Consejo de Estado, de 21 de octubre de 2004, en el que en atención a la posible discordancia entre lo establecido en el artículo I-6 del Tratado y la supremacía de la Constitución, estimó oportuno y conveniente hacer uso de la previsión del artículo 95.2 de la Constitución, a fin de que el Tribunal Constitucional declare si existe o no contradicción entre las estipulaciones del Tratado por el que se establece una Constitución para Europa y la Constitución española.

En Francia, el problema ha sido examinado por el Conseil Constitutionnel ante el que el Presidente de la República había planteado el mismo día de la firma del Tratado, 29 de octubre de 2004, la cuestión de si la autorización para su ratificación debía estar precedida de una modificación de la Constitución francesa.

En su decisión de 19 de noviembre de 2004, el Consejo Constitucional ha estimado, en mi opinión acertadamente, que hay aspectos del Tratado que no exigen previa modificación de la Constitución (los relativos a la primacía del Derecho de la Unión y a la Carta de Derechos Fundamentales), mientras que otros sí exigen modificar la Constitución (disposiciones del Tratado relativas a las políticas y al funcionamiento de la Unión; transferencia de competencias en nuevas materias; nuevas modalidades del ejercicio de competencias ya transferidas; paso a la mayoría cualificada en virtud de una decisión europea ulterior a la entrada en vigor del Tratado; procedimientos de revisión simplificada previstos por los artículos IV-444 y IV-445; y nuevas prerrogativas reconocidas a los Parlamentos nacionales en el marco de la Unión).

En mi opinión, hubiera sido deseable que estas cuestiones hubiesen sido planteadas en la consulta al Tribunal Constitucional; pero no ha sido así, acaso porque en los medios jurídicos españoles el problema central ha sido una «cuestión de juristas»: la de la primacía

8 La problemática de los derechos fundamentales tal como aquí expuesta ha sido anticipada en A. López Pina; I. Gutiérrez, Elementos de Derecho público, Madrid: Marcial Pons Ediciones Jurídicas, 2002, y desarrollada en I. Gutiérrez; J. Alguacil González - Aurioles, Instituciones de Derecho comunitario. Materiales para el estudio, Madrid: UNED, 2004

9 Cfr. J. Vidal - Beneyto, op. cit. 
opinión, vinculará a las constituciones nacionales y a sus intérpretes... Naturalmente, salvo la posibilidad de retirada unilateral.

Añado que el hecho de que la Constitución española no fuera reformada en el pasado, con la salvedad del «y pasivo» del art. 13, sólo prueba que la reforma constitucional en España ha sido tabú durante mucho tiempo. Habría habido que reformar antes nuestra Constitución, para dar fundamento a la pertenencia de España a la Unión Europea, con todas las consecuencias que ello comporta en el ejercicio del poder y en la configuración misma del Estado. Haber errado en el pasado no es justificación para seguir errando. Es hora de que la Constitución española diga que España pertenece a la Unión Europea.

\section{ANTONIO LÓPEZ PINA}

Las transformaciones en el sistema de fuentes del Derecho, en la distribución territorial de las competencias y en el régimen parlamentario, asociadas a la integración europea, vienen, desde 1986, clamando por un aggiornamento de la Constitución Española, que ha llegado el momento de abordar.

Consecuentemente con el dictamen del Consejo de Estado ${ }^{10}$, el Gobierno ha dirigido una consulta al Tribunal Constitucional ${ }^{11}$. La pregunta de la Revista ha sido, así, en cierto modo reformulada, y entiendo que debo ahora responder a la actualización de aquélla por el Gobierno (salvo el apdo. 2. que puede considerarse respondido al hilo de la pregunta $n^{\circ}$ $5)$.

1) Se da por descontada cierta tensión entre el art. 9.1 CE y el art. I-6 TCpE. En los dictámenes y propuestas que han llegado al foro público sobre la forma de resolver posibles antinomias entre la Constitución Española y el art. I-6 TCpE, se ha tendido, por razones del alto coste institucional del art. $168 \mathrm{CE}$ — disolución anticipada de las Cortes, convocatoria de elecciones generales, ratificación por las nuevas Cortes por dos tercios y subsiguiente referendum sobre la reforma-, a excluir la reforma del art. 9.1 CE .

Sin perjuicio de que se trate de unos efectos no desdeñables, más importante me parece, ante la invocación anunciada del art. I-6 TCpE, y no obstante la documentada opinión del Sr. Martínez Lage (vid. EL PAIS, 4 Nov. 2004), en cambio, reforzar la Constitución Española. A tal fin, tengo para mí que la Constitución Española será más fuerte con un art. 9.1 CE confirmado que con un art. 9.1 CE reformado. En tal sentido, y en la expectativa de previsibles colisiones de normas entre el Tratado, el Derecho derivado y nuestra Constitución, me parece de esencial salud jurídica mantener intacta la supremacía de la Constitución.

Ello, sin embargo, no impide que se reconozca, en términos que permitan salvar la contradicción, por ejemplo, en el art. 93 CE, la eficacia propia del Derecho comunitario. El propio Consejo de Estado sugiere incorporar a la Constitución una cláusula general de recepción del Derecho comunitario, sometida, en su caso, a determinadas condiciones materiales y procesales.

Varias constituciones de los Estados establecen en sus cláusulas de integración requisitos estructurales para la organización comunitaria a la que el Estado está dispuesto a confiar el ejercicio de competencias soberanas. El art. 23 GG es la prescripción más explícita:

La República Federal de Alemania participa en la realización de una Europa unida por vía del 
del Derecho de la Unión, proclamado en el artículo I-6 del Tratado.

Creo que se trata de un problema artificioso porque el principio de la primacía del Derecho comunitario sobre el Derecho interno, desarrollado por la jurisprudencia del Tribunal de Justicia de las Comunidades Europeas, está consolidado y ha sido ampliamente asumido por los tribunales supremos y constitucionales de los Estados miembros. ¡Con él venimos viviendo desde enero de 1986 !

Es cierto que algunos de esos tribunales han identificado ciertos límites constitucionales a la primacía del Derecho comunitario derivados especialmente de las normas constitucionales relativas a la protección de los derechos fundamentales y al fundamento constitucional para la atribución de competencias a la Comunidad.

Pero incluso en los ámbitos en lo que existen divergencias dogmáticas profundas entre la concepción del Tribunal de Justicia y la de algunos tribunales nacionales, el alcance de esas divergencias no debe ser exagerado, ya que suele quedar limitado a un plano teórico. Como ha señalado el profesor Gil Carlos Rodriguez Iglesias, resulta significativo que la jurisprudencia constitucional alemana, paradigmática de tales divergencias, no ha llevado nunca a un resultado de conflicto concreto, ni en lo que se refiere al control de las competencias comunitarias ni en lo que concierne a los derechos fundamentales, ámbito éste en el que el Tribunal Constitucional alemán ha dejado claro que sólo podría haber conflicto en el supuesto en que el nivel europeo de protección se apartase de modo general del estándar imperativo de protección del Derecho alemán.

En mi opinión, es así como deben ser interpretados tanto el artículo I-6 del Tratado como la declaración adoptada al respecto por la Conferencia Intergubernamental, del siguiente tenor: «La Conferencia hace constar que el artículo I-6 refleja la jurisprudencia existente del Tribunal de Justicia de las Comunidades Europeas y del Tribunal de Primera Instancia».

Ello no obsta para que en el futuro, en el marco de reformas de la Constitución española, sea deseable la modificación del artículo 93 de la Constitución y que como sugiere el Consejo de Estado en su dictámen, se incorpore al mismo una «cláusula europea» a fin de salvar en el futuro eventuales problemas de compatibilidad entre la Constitución y el Derecho Comunitario. Se trataría de introducir en la propia Constitución, mediante una reformulación del artículo 93, una cláusula de integración que incorpore un mecanismo que permita — con los límites de intangibilidad que se estimen irrenunciables y con los requisitos formales agravados que se consideren necesarios- una apertura general del ordenamiento español al Derecho comunitario.

\section{LUIS MARIA DIEZ-PICAZO}

Pienso que sí sería necesario reformar la Constitución española, especialmente a causa de la inclusión expresa del principio de primacía del Derecho de la Unión Europea. Que ese principio existiera ya en la jurisprudencia no es, a mi juicio, un argumento válido en contra de la necesidad de la reforma constitucional. No es lo mismo acatar una doctrina jurisprudencial, en cuya elaboración que los Estados miembros no han tenido parte alguna, que aceptar explícitamente una norma constitucional. Además, la formulación del principio de primacía en la Constitución para Europa carece de matizaciones, por lo que, en mi 
to constitucional que dote de fundamento para recurrir, a quienquiera que, un día, pueda sentirse lesionado en sus derechos; y, de otro, para que los poderes públicos estatales que actúan en sede de la Unión se vean vinculados por los postulados constitucionales que los jueces y tribunales podrían invocar.

d) El Consejo de Estado sugiere en su Memoria del año 2003 una reforma legal. El Derecho comunitario no tiene en España relevancia constitucional ni es parte del canon de constitucionalidad. En consecuencia, no puede ser aplicado por el Tribunal constitucional, al que sólo compete el juicio de constitucionalidad. Por otra parte, el Derecho comunitario es canon de viabilidad de numerosas disposiciones constitucionales, sobre todo las relativas a la Constitución económica.

A juicio del Consejo de Estado, mediante una reforma del art. 28 de la Ley orgánica del Tribunal Constitucional que hiciera canon de constitucionalidad del Derecho originario de la Unión, tal disfuncionalidad podría ser superada. No parece lógico que, asumido el principio de primacía del Derecho comunitario sobre las normas internas, no tuviese en cuenta el principio de jerarquía normativa (art. 9.3 CE) también las normas comunitarias. El legislador debiera plantearse, así, la conveniencia de que, a la hora de examinar la constitucionalidad de una ley, resolver un conflicto de competencias o enjuiciar desde los valores constitucionales un acto de los poderes públicos, pudiera el Tribunal Constitucional tener en cuenta y aplicar normas europeas. Con ello se conseguiría una mayor coherencia en la interpretación de los Ordenamientos comunitario y español que, teniendo unos mismos destinatarios, deben tender a una aplicación concorde (Consejo de Estado, Memoria del año 2003).

Este planteamiento nació en un tiempo político, bajo el Gobierno del Partido Popular, en el que la reforma constitucional no estaba en el horizonte. Las consecuencias de tipo dogmático e institucional para los dos Ordenamientos, el Tribunal de Justicia de la Unión, el Tribunal Constitucional y los jueces españoles como jueces de Derecho comunitario son de envergadura - incorporaría el Derecho europeo al bloque de la constitucionalidad; colocaría al juez ordinario ante la disyuntiva de haber de optar entre la cuestión de inconstitucionalidad y la cuestión prejudicial, etc. Éste no es el lugar para desgranar ventajas e inconvenientes de la reforma legislativa propuesta por el Consejo de Estado. Sí hay que preguntarse, en cambio, si en la perspectiva de una reforma constitucional no ha perdido su virtualidad.

\section{GIL CARLOS RODRÍGUEZ IGLESIAS}

Cuando esta respuesta se publique, el Tribunal Constitucional se habrá pronunciado sobre la existencia o inexistencia de contradicción entre el Tratado por el que se establece una Constitución para Europa y la Constitución española y, por consiguiente, habrá decidido si es o no necesaria la reforma de la Constitución .

Haciendo abstracción de este elemento — que en realidad es determinante una vez que se ha solicitado la declaración del Tribunal Constitucional— expondré muy brevemente mi opinión personal.

Pienso que el artículo 93 de la Constitución, cuya finalidad primordial ha sido la de hacer posible la participación de España en el proceso de integración europea, y que hasta ahora ha constituido el fundamento constitucional de la adhesión y de la manifestación del 
desarrollo de la Unión Europea, comprometida con los postulados democráticos, de Estado de Derecho, social y federal y con el principio de subsidiariedad, y garantizadora de una protección de los derechos fundamentales homologable en lo esencial con la ofrecida por la Ley Fundamental.

Otras constituciones son menos detalladas, pero requieren asimismo sea una efectiva protección de los derechos, y el respeto a la subsidiariedad y al principio de cohesión social y económica, sea la igualdad de derechos de los Estados -miembros a la hora de formar la voluntad política de la Unión.

La cuestión central reside, pues, en la determinación de las garantías.

2) Quedando así a salvo la reforma del art. 9.1 CE, varias enmiendas parecen aconsejables a fin de garantizar formal y materialmente, ahora y en el futuro, la concordancia entre Constitución y Tratados:

a) El art. $95 \mathrm{CE}$ debe prescribir que, para los tratados aprobados conforme al art. 93 CE, sea preceptiva la consulta al Tribunal Constitucional.

b) El art. 93 CE deberá establecer condiciones formales y materiales a la autorización parlamentaria para suscribir los tratados, por los que se atribuya a una organización o institución internacional el ejercicio de competencias derivadas de la Constitución. Formalmente, deberá satisfacerse el quorum del art. $167 \mathrm{CE}$ en las Cortes Generales. La iniciativa para un referendum al respecto habrá de ser adoptada en los términos previstos por el mismo precepto. Ello, naturalmente, no convierte a los Tratados en normas incorporadas a la Constitución Española o que la modifican. Pero sí garantiza, en cambio, una cierta identidad de formas entre las normas que pueden modificar la Constitución y aquéllas que, mediante la atribución de competencias a la Unión Europea, abren el Derecho español a normas jurídicas que no se someten a las reglas generales, tanto formales como materiales, que, conforme a la Constitución, configuran nuestro Ordenamiento jurídico.

c) La Constitución puede establecer unos límites materiales específicos. Y, así, materialmente, se impone que, para la eficacia en España del Derecho comunitario, el compromiso del Estado requiera que aquél responda al postulado del Estado social y democrático de Derecho y condense los valores de libertad, justicia, igualdad y pluralismo político consagrados en el art. $1 \mathrm{CE}$.

Podrá pensarse que el conflicto material en tales supuestos está excluído. A mi juicio, en cambio, no sólo está el conflicto anunciado, sino que mal avisados estaríamos si no mantuviéramos la Constitución Española en tensión tanto con el Tratado como con el Derecho derivado. La tensión entre el Derecho constitucional de los Estados-miembros y el Tratado de la Unión, que acabamos de ver en el ámbito de los derechos (pregunta $n^{\circ} 5$ ), tiene una segunda vertiente en el principio de homogeneidad constitucional, al que me he referido en la respuesta a la pregunta $n^{\circ}$ 3. Las carencias y flaquezas del Tratado afectan, en particular, a la organización de los poderes, la forma europea de gobierno y los procedimientos de producir Derecho. La homogeneidad constitucional impone también aquí una tensión normativa respecto del Tratado y del Derecho derivado que, al margen de la protección de los derechos, continúan sin conformarse a las tradiciones constitucionales de los Estados-miembros.

La reforma constitucional del art. 93 CE tiene, así, el valor de garantía, de una producción normativa conforme a Derecho frente a un Derecho originario y un Derecho derivado que ni formal ni materialmente muestran vocación de ajustarse a la tradición constitucional española. De ahí, su importancia para que, de un lado, la perspectiva economicista de la garantía comunitaria de los derechos fundamentales tenga el contrapunto de un precep- 
10 Cfr. F. Balaguer Callejón, «Soluciones apócrifas a problemas ficticios. Un comentario al Dictamen del Consejo de Estado sobre el Tratado por el que se establece una Constitución para Europa", Diario La Ley Unión Europea, Martes 30 de Noviembre de 2004

11 1) Existencia o inexistencia de contradicción entre la Constitución Española y el art. I - 6 del Tratado por el que se establece una Constitución para Europa.

2) A la vista de lo que se establece en el art. 10.2 CE, la existencia o inexistencia de contradicción entre la Constitución Española y los arts. II-111 y II-112 TCpE, que forman parte de la Carta de Derechos Fundamentales de la Unión Europea.

3) Suficiencia o no del art. 93 CE, a los efectos de la prestación del consentimiento del Estado al Tratado.

4) En su caso, el cauce de reforma constitucional que hubiera de seguirse para adecuar el texto de la Constitución Española al Tratado por el que se establece una Constitución para Europa. 
consentimiento en obligarse por los distintos tratados posteriores a ésta relativos a las Comunidades europeas y a la Unión Europea, también permitiría la ratificación del Tratado por el que se establece una Constitución para Europa, que no parece contener ninguna disposición que contradiga expresamente una norma constitucional (a diferencia del Tratado de Maastricht, que dio lugar a la primera reforma de la Constitución española después de una Declaración del Tribunal Constitucional) ni tampoco, a mi juicio, implícitamente. Ya he señalado que el principio de primacía de la Constitución y del Derecho de la Unión sobre el Derecho de los Estados miembros — principio al que se refiere especialmente el Dictamen del Consejo de Estado que ha aconsejado solicitar el pronunciamiento del Tribunal Constitucional - no es un principio nuevo Por consiguiente, en mi opinión, la reforma de la Constitución no sería indispensable.

Considero, en cambio, que la reforma es conveniente, si bien podría hacerse con más tranquilidad después de la ratificación del Tratado en el caso de que el Tribunal Constitucional no declare la existencia de una contradicción entre éste y la Constitución española que haga necesaria la reforma.

La reforma es muy conveniente porque cada vez resulta más anómalo que la Constitución española no contenga ninguna referencia expresa a la participación de España en el proceso de integración europea. El artículo 93 está redactado en términos que no reflejan de forma transparente toda su virtualidad.

La reforma constitucional podría hacerse mediante una modificación del propio artículo 93 que haga expresa su condición de fundamento constitucional para la participación de España en el proceso de integración europea o bien, como ha sugerido Pedro Cruz Villalón, mediante una disposición adicional que ponga de manifiesto la condición de miembro de la Unión Europea y establezca una habilitación para seguir participando en la profundización del proceso de integración. 
